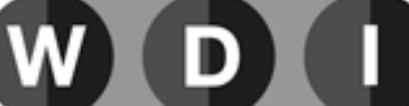

William Davidson Institute

AT THE UNIVERSITY OF MICHIGAN

Bank Competition and Financial Stability:

Much Ado About Nothing?

By: Diana Zigraiova and Tomas Havranek

William Davidson Institute Working Paper Number 1087 January 2015 


\title{
Bank Competition and Financial Stability: Much Ado About Nothing?*
}

\author{
Diana Zigraiova ${ }^{\mathrm{a}, \mathrm{b}}$, Tomas Havranek ${ }^{\mathrm{a}, \mathrm{b}}$ \\ ${ }^{a}$ Czech National Bank \\ ${ }^{\mathrm{b}}$ Charles University, Prague
}

January 1, 2015

\begin{abstract}
The theoretical literature gives conflicting predictions on how bank competition should affect financial stability, and dozens of researchers have attempted to evaluate the relationship empirically. We collect 598 estimates of the competition-stability nexus reported in 31 studies and analyze the literature using meta-analysis methods. We control for 35 aspects of study design and employ Bayesian model averaging to tackle the resulting model uncertainty. Our findings suggest that the definition of financial stability and bank competition used by researchers influences their results in a systematic way. The choice of data, estimation methodology, and control variables also affects the reported coefficient. We find evidence for moderate publication bias. Taken together, the estimates reported in the literature suggest little interplay between competition and stability, especially in developing and transition countries, even when corrected for publication bias and potential misspecifications.
\end{abstract}

Keywords: Bayesian model averaging, bank competition, financial stability, publication selection bias, meta-analysis

JEL Codes: C83, C11, G21, L16

\footnotetext{
* Corresponding author: Diana Zigraiova, diana.zigraiova@cnb.cz. An online appendix with data and code is available at http://meta-analysis.cz/competition. We acknowledge support from the Czech Science Foundation (grant \#15-02411S). The views expressed here are ours and not necessarily those of the Czech National Bank.
} 


\section{Introduction}

The theory does not provide clear guidance on the expected sign of the relationship between bank competition and financial stability. On the one hand, the competition-fragility hypothesis (represented, for example, by Keeley, 1990) argues that competition hampers stability. Strong competition in the banking sector forces banks to take on excessive risks in the search for yield, which leads to overall fragility of the financial system. On the other hand, under the competition-stability hypothesis (for instance, Boyd and De Nicolo, 2005), increased competition makes the financial system more resilient. A competitive banking sector results in lower lending rates, which support firms' profitability, leading to lower credit risk for banks. Moreover, in uncompetitive environments banks are more likely to rely on their too-big-to-fail position and engage in moral hazard (Mishkin, 1999). Since the early 2000s, dozens of researchers have reported estimates of the competition-stability nexus, but their results vary. As Figure 1 shows, the dispersion of the results increases as time passes, complicating our inference from the literature.

Figure 1: The reported estimates of the competition-stability nexus diverge

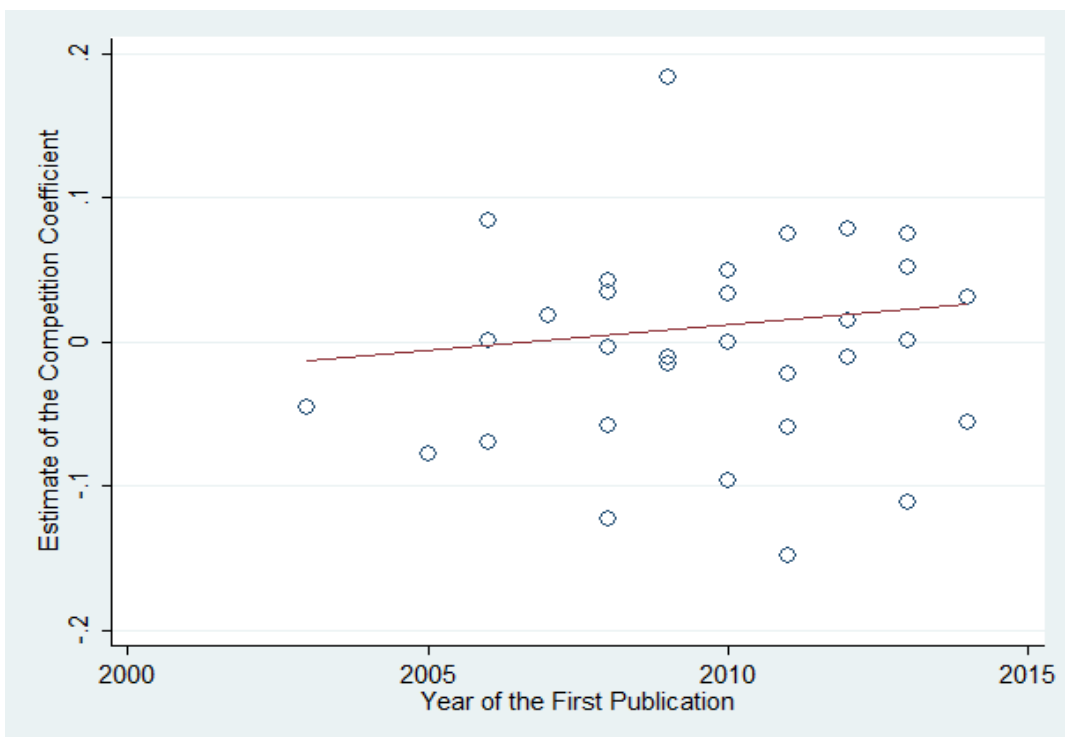

Notes: The figure depicts the median partial correlation coefficients corresponding to the effects of banking competition on financial stability reported in individual studies. The horizontal axis measures the year when the first drafts of the studies appeared in Google Scholar. The line shows the linear fit (the slight upward trend is not statistically significant).

When the literature lacks patterns visible at first sight, narrative surveys are useful in discussing the reasons for the heterogeneity observed in the results, but they cannot provide policy makers and other researchers with clear guidelines concerning the relationship in question. Our aim in this paper is to collect all available estimates of the relation between bank competition and financial stability, and examine them using up-to-date meta-analysis methods. Meta-analysis is 
most commonly applied in medical research to synthesize the results of clinical trials, and the use of this method dates back at least to Pearson (1904). Meta-analysis later spread to the social sciences, including economics and finance, and examples of early applications are summarized by Stanley (2001). Recent applications of meta-analysis include Chetty et al. (2011), who explore the intertemporal elasticity of substitution in labor supply, Doucouliagos et al. (2012), who investigate the link between chief executives' pay and corporate performance, and Babecky and Havranek (2014), who evaluate the impact of structural reforms on economic growth.

We collect 598 estimates of the competition-stability nexus from 31 studies published between 2003 and 2014, and present, to our knowledge, the first meta-analysis on the topic. We do not find evidence for any robust relationship between bank competition and financial stability: either the positive and negative effects of competition offset each other, or current data and methods do not allow researchers to identify the relationship. This conclusion holds even when we account for publication selection bias and potential misspecifications in the literature.

Publication bias results from selective reporting of different empirical results. As Stanley (2001) notes, the bias can stem from a preference for estimates that are either statistically significant or consistent with a mainstream theory. The selection can occur at any stage of the publication process: authors may think that unintuitive results may be difficult to publish, so they put more weight on estimates that are easier to explain. Similarly, they might prefer statistically significant results, because in many cases insignificant estimates appear hard to sell. Journal editors and referees may display similar preferences. A recent survey of studies on publication selection bias in economics (Doucouliagos and Stanley, 2013) suggests that the problem is widespread and that unpublished manuscripts often show such bias as well. In our case there are opposing theories concerning the effect of competition on stability, so both positive and negative estimates are publishable. Indeed, our results suggest that publication bias in the literature is not strong, but some authors still tend to preferentially report negative estimates (in line with the competition-fragility hypothesis), which biases the mean reported estimate downward.

The studies estimating the effect of bank competition on financial stability differ greatly in terms of the data and methodology used. We account for 35 aspects of studies and estimates, including the length of the sample, regional coverage, the definitions of key variables, the inclusion of controls, the estimation methodology, and publication characteristics (such as the number of citations of the study and the impact factor of the journal). We explore how these aspects affect the reported estimates, and use Bayesian model averaging (BMA; Raftery et al., 1997) to address model uncertainty. BMA is especially useful in meta-analysis, because for many study aspects there is no theory telling us how they should influence the results. Our findings indicate that researchers' choices concerning the data used, the definitions of key variables, and the estimation methodology affect the reported estimates systematically. We also find that highly cited studies published in good journals tend to report larger estimates of the competition-stability nexus. Finally, using all the estimates we construct a synthetic study, for which we select the methodology and publication aspects that we prefer (such as control for endogeneity and the maximum number of citations). The resulting estimate of the competitionstability nexus is very small. 
The paper is organized as follows. Section 2 briefly discusses the related literature on the topic and explains how the effect of bank competition on financial stability is estimated. Section 3 explains how we collect the estimates and re-compute them to a common metric (partial correlation coefficients). Section 4 tests for the presence of publication bias. Section 5 describes the sources of heterogeneity in the literature and provides estimates of the competition-stability nexus conditional on our definition of best practice. In Section 6 we perform robustness checks using alternative priors for BMA and a more homogeneous subsample of estimates. Section 7 concludes. Appendix A presents diagnostics of the BMA exercise, and Appendix B lists the studies included in the meta-analysis.

\section{Estimating the Effect of Bank Competition on Financial Stability}

The impact of bank competition on financial stability remains a controversial issue in the theoretical literature. Two opposing theories - the competition-stability hypothesis and the competition-fragility hypothesis - can be used to justify the conflicting results often found in empirical studies.

The competition-fragility hypothesis asserts that more competition among banks leads to instability of the financial system. Marcus (1984) and Keeley (1990) model theoretically the "charter value" proposition, where banks choose the risk level of their asset portfolios. In the setting of limited liability, bank owners, who are often given incentives to shift risks to depositors, tend to engage only in the upside part of the risk-taking process. In more competitive systems, this behavior places substantial emphasis on profits: banks have higher incentives to take on excessive risks, which leads to higher instability of the system in general. In addition, in competitive systems the incentives of banks to properly screen borrowers are reduced, which again contributes to system fragility (Allen and Gale, 2000; Allen and Gale, 2004; Boot and Thakor, 1993). Conversely, when entry barriers are in place and competition in the sector is limited, banks have better profit opportunities and larger capital cushions and, therefore, are not prone to taking aggressive risks. In this framework highly concentrated banking systems contribute to overall financial stability (Boot and Greenbaum, 1993; Hellman, Murdoch, and Stiglitz, 2000; Matutes and Vives, 2000).

The competition-stability hypothesis, on the other hand, proposes that more competitive banking systems imply less fragility of the financial system. Specifically, Boyd and De Nicolo (2005) show that lower client rates facilitate lending as they reduce entrepreneurs' cost of borrowing. Lower costs of borrowing raise the chance of investment success, which, in turn, lowers banks' credit portfolio risk and leads to increased stability within the sector. Some theoretical studies reveal that banks in uncompetitive systems are more likely to originate risky loans, which pave the way to systemic vulnerabilities (Caminal and Matutes, 2002). Similarly, Mishkin (1999) stresses that, in concentrated systems, regulators are prone to implement toobig-to-fail policies that encourage risk-taking behavior by banks. 
Overall, it appears that empirical studies conducted for individual countries do not find conclusive evidence for either the stability-enhancing or the stability-deteriorating view of competition (Fungacova and Weill, 2009; Fernandez and Garza-Garciab, 2012; Liu and Wilson, 2013). Some of the cross-country literature shows that more competitive banking systems are less likely to experience a systemic banking crisis (Beck et al., 2006a; Schaeck et al., 2009). In contrast, other studies (Yeyati and Micco, 2007; Uhde and Heimeshoff, 2009; Boyd et al., 2006) reveal that in more competitive systems bank failures tend to be more frequent. Further research also provides evidence that in more concentrated systems banks have higher capital ratios, which offsets the possibly stronger risk-taking behavior on their part (Berger et al., 2009; Schaeck and Cihak, 2012).

In this meta-analysis we focus on variants of the following model used in the literature to examine the effect of bank competition on stability:

$$
\text { Stability }_{i t}=\alpha+\beta \cdot \text { Competition Measure } e_{i t}+\sum_{k=1}^{N} \gamma_{k i t} X_{k i t}+e_{i t},
$$

where $i$ is a bank index and $t$ a time index and $X$ is a set of control variables, both bank-specific and country-specific. Measures of stability and competition tend to vary across individual studies, as we will discuss later in this section (the various estimation methods used by researchers will be discussed in Section 5). We are interested in the coefficient $\beta$.

Bank stability is often measured in an indirect way, that is, by considering individual or systemic banking distress, effectively the negative of stability. In this spirit, the non-performing loan (NPL) ratio is often used as a fragility indicator. Nevertheless, the NPL ratio only covers credit risk and cannot be directly linked to the likelihood of bank failure (Beck, 2008). Another measure of individual bank distress extensively used in the literature is the Z-score (e.g. Boyd and Runkle, 1993; Lepetit et al., 2008; Laeven and Levine, 2009; Cihak and Hesse, 2010). This measure indicates how many standard deviations in return on assets a bank is away from insolvency and, by extension, from the likelihood of failure. The Z-score is calculated as follows:

$$
Z_{i t}=\frac{R O A_{i t}{ }^{+} E_{i t} / T A_{i t}}{\sigma_{R O A_{i t}}}
$$

where $\mathrm{ROA}$ is the rate of return on assets, $\mathrm{E} / \mathrm{TA}$ is the ratio of equity to total assets, and $\sigma_{R O A}$ is the standard deviation of the return on assets. Bank profitability, measured by ROA and ROE, profit volatility, approximated by ROA and ROE volatility, and bank capitalization, expressed by the capital adequacy ratio (CAR) or the ratio of equity to total bank assets, are additional measures of individual bank distress frequently used in the literature. Moreover, some studies (e.g. Beck, Demirguc-Kunt, and Levine, 2006a,b) model fragility in the banking sector by means of systemic banking crisis dummies. Other studies (such as Fungacova and Weill, 2009) apply individual bank failure dummies or measures of a bank's distance-to-default to proxy financial stability. 
Concerning the proxies for competition, the Lerner index is one of the indicators frequently employed in the literature. This index quantifies the price power capacity of a bank by expressing the difference between price and marginal cost as a percentage of the price:

$$
\text { Lerner }_{i t}=\frac{\left(P_{T A_{i t}}-M C_{T A_{i t}}\right)}{P_{T A_{i t}}},
$$

where $P_{T A_{i t}}$ is the price of total assets, expressed in practice by total revenues to total bank assets, and $M C_{T A_{i t}}$ is the marginal cost of total assets for bank $i$. The index thus takes values between 0 and 1 , with the values of 0 and 1 reached only in the case of perfect competition and under pure monopoly, respectively. Alternatively, the degree of competition in the banking sector can be measured by the so-called H-statistic, introduced by Panzar and Rosse (1987). The H-statistic measures competition by summing the elasticities of a bank's revenue with respect to its input prices. Another competition measure, the Boone (2008) indicator, applied by Schaeck and Cihak (2012), for example, expresses the effect of competition on the performance of efficient banks and offers an organization-based explanation for how competition can improve stability.

In addition, concentration ratios were originally used as bank competition proxies: for instance, the Herfindahl-Hirschman index and the $\mathrm{C} 3$ concentration ratio, which indicates the share of the three largest banks' assets in the total assets of the country's banking system. Nevertheless, some studies (e.g. Claessens and Laeven, 2004) have shown that bank concentration is not an adequate indicator of the competitive nature of the system, as concentration and competition highlight different banking sector characteristics. In the spirit of better erring on the side of inclusion in meta-analysis (Stanley, 2001), we also collect estimates that measure competition by the inverse of concentration, and conduct a robustness check where we exclude these estimates.

\section{The Data Set of Competition-Stability Estimates}

The first step in any meta-analysis is to collect estimates from primary studies. We search for studies relevant to our meta-analysis using the Google Scholar and RePEc search engines and the following combinations of keywords: "competition" and "stability," "competition" and "fragility," "concentration" and "stability," and "concentration" and "fragility." We collect both published and unpublished studies, and try to include as many papers as possible. Since we need standard errors of the estimates to be able to use up-to-date meta-analysis methods, we have to omit studies that do not report statistics from which standard errors can be computed. In the end, we are left with 31 studies, which report 598 estimates. We also collect 35 variables reflecting the context in which researchers obtain their estimates. Our data collection strategy, as well as all other aspects of this meta-analysis, conform to the Meta-Analysis of Economics Research Reporting Guidelines (Stanley et al., 2013).

Given the broad scope of the measures used in the literature to proxy for both bank competition and financial stability, it is imperative that we recompute the individual estimates to 
a common metric. Because some stability proxies measure financial fragility and some competition proxies investigate how uncompetitive the market is (for example, larger values of the Lerner index imply a less competitive nature of the system), we adjust the signs of the collected estimates so that they directly reflect the relationship between competition and stability. After this adjustment the collected estimates imply either that higher competition increases bank stability or that higher competition decreases bank stability, and they could be compared with each other if all studies used the same units of measurement.

Due to the inconsistency in the use of measurement units of regression variables in the literature, we transform the reported estimates into partial correlation coefficients (PCCs). The PCC is a unitless measure of the strength and direction of the association between two variables, competition and stability in our case, while holding other variables constant (Stanley and Doucouliagos, 2012). The PCCs enable us to directly compare estimates reported in different studies. This technique is widely used in meta-analysis research nowadays; a related application can be found, for example, in Valickova et al. (2014).

The partial correlation coefficient is calculated according to the following formula:

$$
P C C=\frac{t}{\sqrt{t^{2}+d f}}
$$

where $t$ is the t-statistic of the reported coefficient and $d f$ denotes the number of degrees of freedom used for the estimation. The corresponding standard errors of the PCC are calculated as follows:

$$
S E P C C=\sqrt{\frac{\left(1-P C C^{2}\right)}{d f}} .
$$

Moreover, if the primary study assumes a quadratic relationship between competition and stability and thus reports two coefficients associated with the measure of competition, the overall impact on stability needs to be linearized using the following formula:

$$
\beta=\widehat{\beta_{1}}+\widehat{\beta_{2}} \bar{x} \quad S E(\beta)=\sqrt{S E\left(\widehat{\beta_{1}}\right)^{2}+4 S E\left({\widehat{\beta_{2}}}^{2} \bar{x}^{2}\right.}
$$

where $\widehat{\beta_{1}}$ is the estimate of the competition coefficient for the linear term, $\widehat{\beta_{2}}$ is the estimate of the competition coefficient for the quadratic term, $\bar{x}$ is the sample mean of the competition measure in the study, $S E\left(\widehat{\beta_{1}}\right)$ is the standard error of the reported coefficient for the linear term, and $S E\left(\widehat{\beta_{2}}\right)$ is the standard error of the reported coefficient for the quadratic term. The covariance term is omitted from the $S E(\beta)$ formula due to the unavailability of the original data. The resulting coefficient of bank competition after linearization is subsequently transformed into the PCC in line with equations (4) and (5).

Figure 2 depicts the within- and between-study dispersion in the partial correlation coefficients of the competition-stability estimates reported in the 31 studies that we examine in this metaanalysis. It is apparent that the literature is highly heterogeneous, both between and within studies. Meta-analysis will help us to formally trace the sources of this heterogeneity. 
Figure 2: Variability in the estimated competition coefficients across individual studies

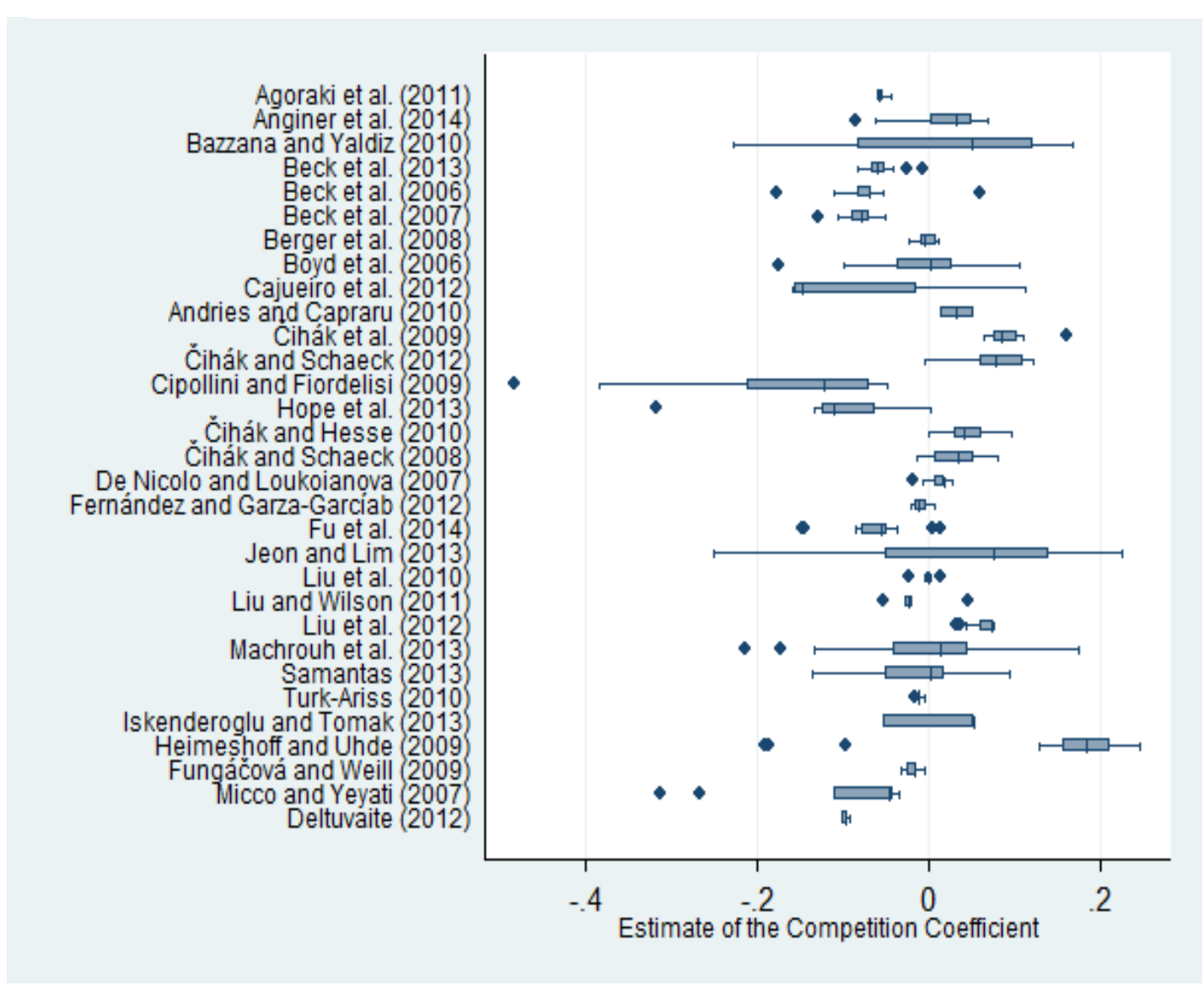

Notes: The figure shows a box plot of the PCCs of the competition coefficient estimates (the PCCs of the $\beta$ estimates from equation (1)) reported in individual studies. Full references for the studies included in the meta-analysis are available in Appendix B.

Table 1: Estimates of the competition effect for different country groups

\begin{tabular}{c|ccc|ccc|c} 
& \multicolumn{3}{|c|}{ Unweighted } & \multicolumn{3}{c|}{ Weighted } & No. of estimates \\
& Mean & 95\% Conf. Int. & Mean & $95 \%$ Conf. Int. & \\
\hline All & -0.001 & -0.025 & 0.023 & -0.012 & -0.035 & 0.011 & 598 \\
Developed & 0.020 & -0.032 & 0.073 & 0.011 & -0.030 & 0.052 & 201 \\
Developing & 0.001 & -0.022 & 0.023 & -0.019 & -0.051 & 0.012 & 194 \\
and transition & & & &
\end{tabular}

Notes: The table presents the mean PCCs of the competition coefficient estimates (the PCCs of the $\beta$ estimates from equation (1)) over all countries and for selected country groups. The confidence intervals around the mean are constructed using standard errors clustered at the study level. In the right-hand part of the table the estimates are weighted by the inverse of the number of estimates reported per study.

Table 1 shows summary statistics for all the estimates and for two subsamples of the estimates that evaluate the effect for developed and developing countries. All the means reported in Table 1 are close to zero, indicating little interplay between competition and stability. The 
means of the competition coefficient estimates for developed countries are slightly larger than those for developing and transition countries. (The overall mean is slightly negative, while the means for both developing and developed countries are positive, which suggests that studies that mix these two groups tend to find smaller estimates of the effect.) No strong inference can be made, however, as none of the reported means is significant at the $5 \%$ level of significance. Moreover, all these values are negligible and would be classified as implying no effect according to the guidelines for the interpretation of partial correlation coefficients in economics (Doucouliagos, 2011).

Figure 3 depicts the distribution of the partial correlation coefficients of all the competition coefficient estimates. It appears that the PCCs are symmetrically distributed around zero with a mean of -0.0009 , while the mean of the study-level medians is also close to zero and equals 0.0099. We also report the mean of the PCCs of the estimates that are reported in studies published in peer-reviewed journals, as opposed to those reported in unpublished manuscripts. In total, 21 of the 31 studies in our sample were published in peer-reviewed journals, yielding 376 estimates of the competition coefficient. The mean for published studies is 0.0116: it appears that journals tend to report slightly larger estimates of the competition coefficient compared to the grey literature.

Figure 3: Studies published in journals report slightly larger estimates

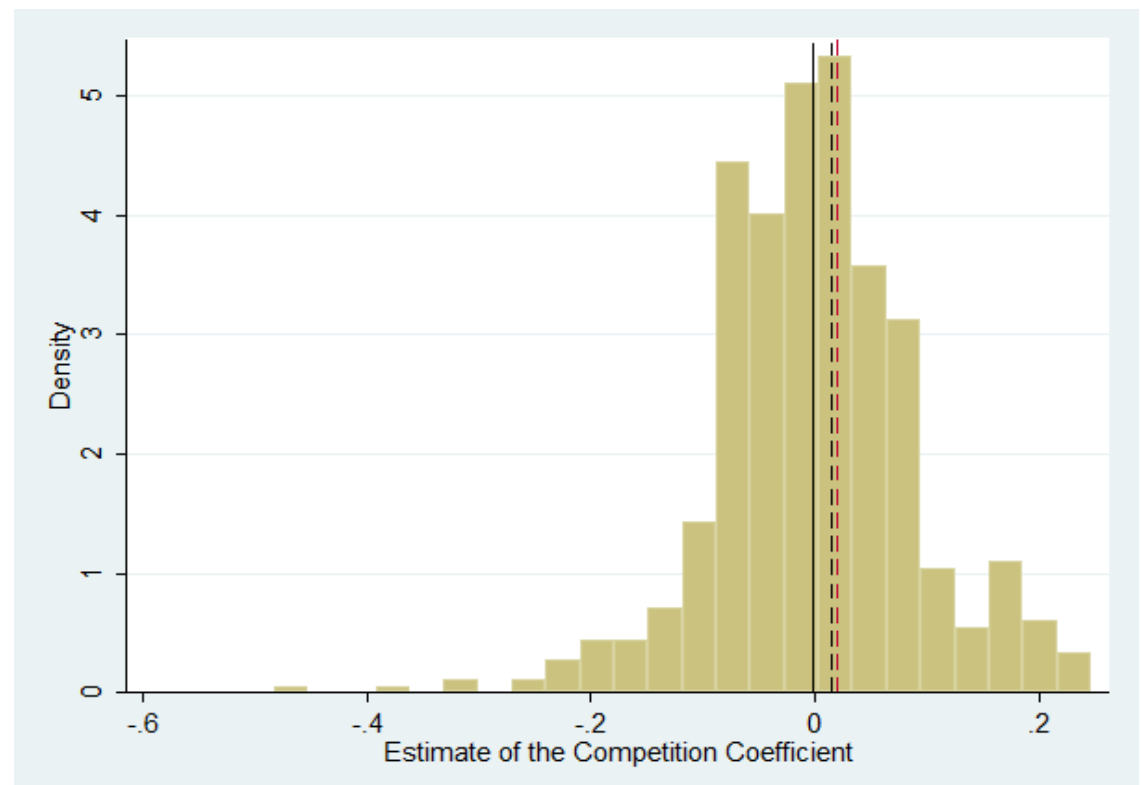

Notes: The figure shows the histogram of the PCCs of the competition coefficient estimates (the PCCs of the $\beta$ estimates from equation (1)) reported in individual studies. The solid vertical line denotes the mean of all the PCCs. The dashed lines denote the mean of the median PCCs of the estimates from the studies and the mean of the PCCs of those estimates that are reported in studies published in peer-reviewed journals, respectively. 


\section{Testing for Publication Bias}

Publication selection bias arises when an estimate's probability of being reported depends on its sign or statistical significance. Rosenthal (1979) refers to this phenomenon as the "file drawer problem,” implying that researchers may hide estimates that are either insignificant or have a counterintuitive sign in their file drawers, and seek instead to obtain new estimates that would be easier to publish. A number of studies, e.g., by DeLong and Lang (1992), Card and Krueger (1995), and Ashenfelter et al. (1999), identify publication selection bias in empirical economics. In addition, Doucouliagos and Stanley (2013) conduct a survey of meta-analyses and find that most fields of empirical economics suffer from publication bias. The bias tends to inflate the mean estimates reported by empirical studies. For example, Doucouliagos and Stanley (2009) estimate that the adverse employment effect of minimum wage increases is seriously overstated in the published empirical literature. In this section, we test for potential publication bias in the literature evaluating the competition-stability nexus before we proceed with the analysis of heterogeneity in the next section.

We start with visual tests for the presence of publication bias. The most commonly applied graphical test uses the so-called funnel plot (Egger et al., 1997), which depicts the magnitude of the estimated effect on the horizontal axis and precision (the inverse of the estimated standard error) on the vertical axis. The most precise estimates (located at the top of the funnel) should be close to the true underlying effect. With decreasing precision, the estimates get more dispersed; overall, they should form a symmetrical inverted funnel. If there is publication bias in the literature, the funnel is either asymmetrical due to the exclusion of estimates of a certain sign or size, or hollow due to the omission of insignificant estimates, or displays both these properties.

Figure 4A shows the funnel plot for the PCCs of all the competition coefficient estimates reported in the studies, while Figure $4 \mathrm{~B}$ depicts the funnel plot for the median values of the PCCs of the estimates reported in individual studies.

Figure 4: Funnel plots do not suggest strong publication bias

A) All estimates

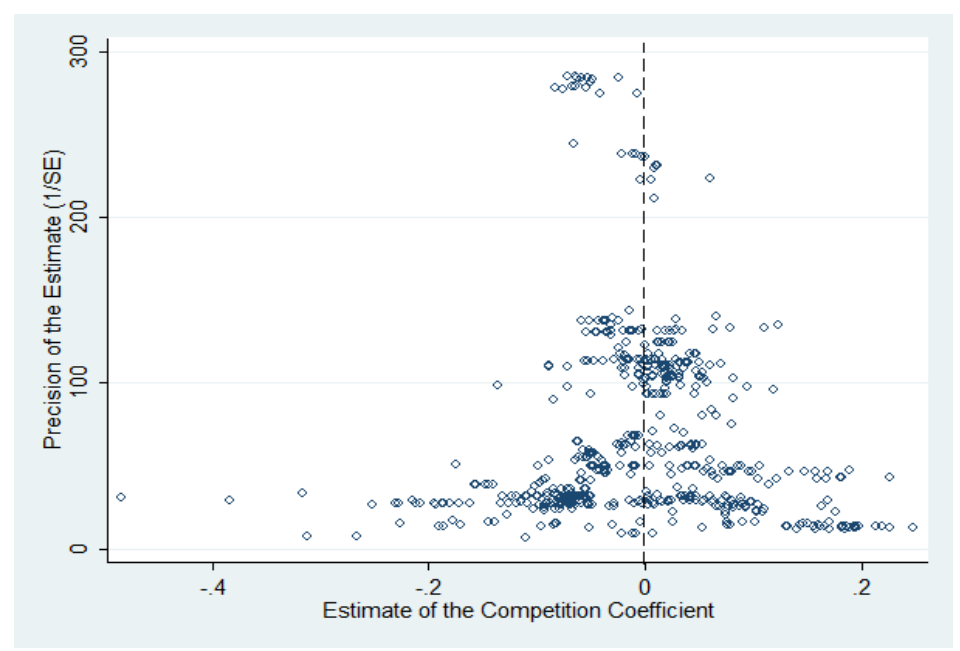


B) Median estimates from studies

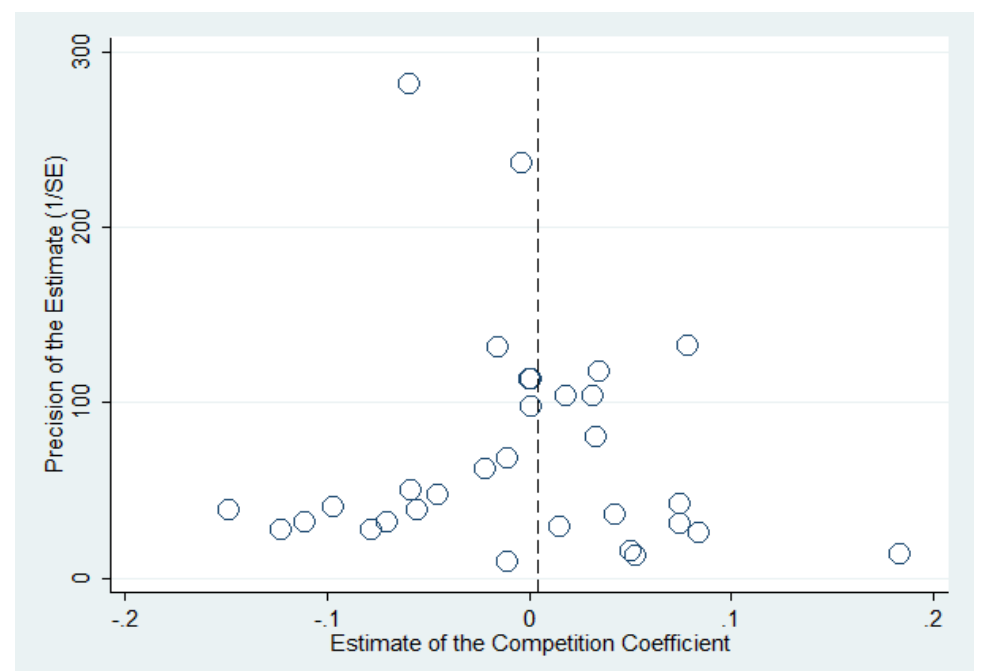

Notes: In the absence of publication bias the funnel should be symmetrical around the most precise estimates of the competition coefficient (the PCC of the $\beta$ estimate from equation (1)). The dashed vertical lines denote the mean of the PCCs of all the estimates in Figure $4 \mathrm{~A}$ and the mean of the study-level medians reported in Figure 4B.

We observe that both funnels are relatively symmetrical, and the most precise estimates are close to the mean reported PCC of the estimates. Moreover, the funnels are not hollow, and even estimates with very little precision (and large p-values) at the bottom of both plots are reported. Therefore, we can infer that these funnel plots do not point to the presence of publication bias in the competition-stability literature, as opposed to the findings in most other fields in economics and finance (for example, Havranek and Kokes, 2014).

A more rigorous approach to testing for publication bias consists in funnel asymmetry tests. These tests explore the relationship between the collected coefficient estimates and their standard errors following the methodology suggested by Card and Krueger (1995). In the presence of publication selection, the reported estimates are correlated with their standard errors. For example, if negative estimates are omitted, a positive relationship appears between the reported coefficient estimates and their standard errors because of heteroskedasticity in the equation (Stanley, 2008). Similarly, researchers who prefer statistical significance need large estimates to offset large standard errors. Thus, we estimate the following equation:

$$
P C C_{i}=\beta_{0}+\beta_{1} S E\left(P C C_{i}\right)+\varepsilon_{i}
$$

where $P C C_{i}$ is the partial correlation coefficient of the competition coefficient estimate, $S E\left(P C C_{i}\right)$ is the standard error of the partial correlation coefficient, $\beta_{0}$ is the mean PCC corrected for the potential publication bias, $\beta_{1}$ measures the extent of publication bias, and $\varepsilon_{i}$ is 
a disturbance term. Equation (7) is commonly called the funnel asymmetry test, as it follows from rotating the axes of the funnel plot and inverting the values on the new horizontal axis so that it now shows standard errors instead of precision.

The results of the funnel asymmetry tests are presented in Table 2. The coefficient estimates in the upper part of the table result from fixed effects estimation with standard errors clustered at the level of individual studies and from instrumental variable estimation (where the number of observations is used as an instrument for the standard error). Fixed effects control for method or other quality characteristics specific to individual studies. We also report results for the subsample of estimates reported in published studies to see whether they show different levels of publication selection bias. The bottom half of the table presents results from regressions weighted by the inverse of the number of estimates reported per study in order to diminish the effect of studies reporting many estimates. In all specifications in Table 2, both coefficient estimates are significant at least at the $5 \%$ level. A moderate negative publication bias is present, and the estimated size of the competition-stability effect beyond publication bias appears to be close to zero (again, negligible according to the guidelines by Doucouliagos, 2011).

Table 2: Funnel asymmetry tests show moderate publication bias

\begin{tabular}{|c|c|c|c|c|}
\hline Unweighted regressions & Fixed Effects & $\begin{array}{c}\text { Fixed } \\
\text { Effects_Published } \\
\end{array}$ & Instrument & Instrument_Published \\
\hline SE (publication bias) & $-1.671^{* *}$ & $-1.898^{* *}$ & $-1.614^{* * *}$ & $-2.291 * * *$ \\
\hline Constant (effect beyond bias) & $0.044^{* *}$ & $0.073^{* *}$ & $0.043^{* * *}$ & $0.086^{* * *}$ \\
\hline No. of estimates & 598 & 376 & 598 & 376 \\
\hline No. of studies & 31 & 21 & 31 & 21 \\
\hline Weighted regressions & \multicolumn{2}{|c|}{ Fixed Effects } & \multicolumn{2}{|c|}{ Fixed Effects_Published } \\
\hline SE (publication bias) & \multicolumn{2}{|r|}{$-1.568^{* * *}$} & \multicolumn{2}{|r|}{$-1.636^{* * *}$} \\
\hline Constant (effect beyond bias) & \multicolumn{2}{|r|}{$0.034^{* * *}$} & \multicolumn{2}{|r|}{$0.044^{* * *}$} \\
\hline No. of estimates & \multicolumn{2}{|r|}{598} & \multicolumn{2}{|r|}{376} \\
\hline No. of studies & \multicolumn{2}{|r|}{31} & \multicolumn{2}{|r|}{21} \\
\hline
\end{tabular}

Notes: The table presents the results of the regression specified in equation (6). The standard errors of the regression parameters are clustered at the study level. Published $=$ we only include published studies. Fixed Effects = we use study dummies. Instrument $=$ we use the logarithm of the number of observations in equation (1) as an instrument for the standard error and employ study fixed effects. The regressions in the bottom half of the table are estimated by weighted least squares, where the inverse of the number of estimates reported per study is taken as the weight. ${ }^{* * *},{ }^{* *}$, and * denote statistical significance at the $1 \%, 5 \%$, and $10 \%$ level.

The magnitude of the publication bias is slightly larger in published studies than in unpublished manuscripts, but the difference is not statistically significant. We consider it remarkable that the fixed effects and instrumental variable specifications yield very similar results. In meta-analysis it is important to check for endogeneity of the standard error, because very often it can happen that the meta-analyst cannot collect all relevant information on the methodology used in the primary studies. If the meta-analyst omits an aspect of methodology that influences both the reported coefficients and their standard errors in the same direction, he or she will obtain 
biased estimates of the magnitude of the publication bias. Our results suggest that in the case of the competition-stability nexus endogeneity is not an important issue.

Equation (7), however, suffers from heteroskedasticity, because the explanatory variable directly captures the variance of the response variable. To achieve efficiency, many meta-analysis applications divide equation (7) by the corresponding standard error, i.e., they multiply the equation by the precision of the estimates. This specification places more emphasis on precise results. Dividing equation (7) by the corresponding SE of the PCC, we obtain the following equation:

$$
t_{i}=\beta_{1}+\beta_{0}\left(1 / S E\left(P C C_{i}\right)\right)+\mu_{i},
$$

where $\beta_{0}$ is the mean PCC of the coefficient estimate corrected for the potential publication bias, $\beta_{1}$ measures the extent of publication bias, and $t_{i}$ is the corresponding t-statistic. Table 3 below presents results from the heteroskedasticity-corrected equation (8).

Table 3: Heteroskedasticity-corrected funnel asymmetry tests confirm the presence of publication bias

\begin{tabular}{ccc|cc} 
Weighted by precision & Fixed Effects & $\begin{array}{c}\text { Fixed } \\
\text { Effects_Published }\end{array}$ & Instrument & Instrument_Published \\
\hline 1/SE (effect beyond bias) & 0.005 & 0.065 & $0.019^{* *}$ & $0.053^{* * *}$ \\
Constant (publication bias) & -0.757 & $-4.000^{*}$ & $-1.706^{* *}$ & $-3.344^{* * *}$ \\
\hline No. of estimates & 598 & 376 & 598 & 376 \\
No. of studies & 31 & 21 & 31 & 21 \\
\hline Weighted by precision and & \multicolumn{2}{c|}{ Fixed Effects } & \multicolumn{2}{c}{ Fixed Effects_Published } \\
no. of observations & 0.013 & & $0.056^{* *}$ \\
\hline 1/SE (effect beyond bias) & \multicolumn{3}{c|}{$-539^{* *}$} & 376 \\
Constant (publication bias) & 598 & 21 \\
\hline No. of estimates & 31 &
\end{tabular}

Notes: The table presents the results of the regression specified in equation (7). The standard errors of the regression parameters are clustered at the study level. Published $=$ we only include published studies. Fixed Effects = we use study dummies. Instrument = we use the logarithm of the number of observations in equation (1) as an instrument for the standard error and employ study fixed effects. The regressions in the bottom half of the table are additionally weighted by the inverse of the number of estimates reported per study. ${ }^{* * *},{ }^{* *}$, and * denote statistical significance at the $1 \%, 5 \%$, and $10 \%$ level.

We can observe from Table 3 that publication bias is not equally strong across all specifications, in contrast to Table 2. Moreover, the true underlying effect beyond publication bias is only significant when equation (8) is estimated by means of instrumental variables or by fixed effects for the subsample of published studies. Table 3 confirms that the competition-stability effect beyond publication bias is indeed close to zero, as no estimate surpasses the threshold defined by Doucouliagos (2011) to denote at least a weak effect. The story changes for publication bias, which now seems to be much stronger in published studies than in unpublished manuscripts, which would suggest that journal editors or referees prefer papers that show results consistent with the competition-fragility hypothesis. 
For evaluation of the extent of publication bias, Doucouliagos and Stanley (2013) provide guidelines for the value of the constant in the funnel asymmetry test specified by equation (8). They identify that the literature suffers from substantial selectivity if $\hat{\beta}_{1}$ from equation (8) is statistically significant and, at the same time, $1 \leq\left|\hat{\beta}_{1}\right| \leq 2$. Both conditions hold for the value of the constant estimated by fixed effects and weighted by the inverse of the number of observations, as well as for the constant in regressions estimated by the instrumental variable method. The values of the coefficient estimated in Table 3 for published studies are even larger than 2, which would suggest severe publication bias according to the guidelines by Doucouliagos and Stanley (2013). Nevertheless, we believe the overall evidence points to only moderate publication bias, because the corrected estimates of the competition-stability nexus are close to the simple mean of all the estimates uncorrected for publication bias.

\section{Why the Reported Coefficients Vary}

\subsection{Variable Description and Methodology}

In this section we add the characteristics of the studies and estimates into equation (7) to explore what drives the heterogeneity in the literature. We do not weight the resulting equation by precision as is the case in equation (8): weighting by the estimates' precision introduces artificial variation into variables either that are defined at the study level (for example, the impact factor of the study) or that tend to vary little within studies (for example, sample size). In contrast, we weight the regressions by the inverse of the number of estimates reported per study to give the same importance to each study in our data set. In the next section we also perform a robustness check for regressions not weighted by the number of estimates per study.

Table 4 describes all the variables that we collect from the primary studies. For each variable the table also shows the mean, the standard deviation, and the mean weighted by the inverse of the number of estimates reported per study. For ease of exposition we divide the collected variables into eight groups.

Table 4: Overview and summary statistics of the regression variables

\begin{tabular}{|c|c|c|c|c|}
\hline Variable & Description & Mean & SD & WM \\
\hline \multicolumn{5}{|l|}{ Data characteristics } \\
\hline $\begin{array}{l}\text { Competition } \\
\text { coefficient }\end{array}$ & $\begin{array}{l}\text { The coefficient capturing the effect of bank competition on } \\
\text { financial stability (recomputed to the partial correlation coeff.) }\end{array}$ & -0.001 & 0.090 & -0.012 \\
\hline SEPCC & The estimated standard error of the competition coefficient & 0.027 & 0.022 & 0.029 \\
\hline Samplesize & $\begin{array}{l}\text { The logarithm of the number of cross-sectional units used in the } \\
\text { competition-stability regression }\end{array}$ & 7.835 & 1.615 & 7.760 \\
\hline $\mathrm{T}$ & The logarithm of the number of time periods (years) & 2.224 & 0.743 & 2.264 \\
\hline sampleyear & $\begin{array}{l}\text { The mean year of the sample period on which the competition- } \\
\text { stability regression is estimated (base: } 1992,5 \text { ) }\end{array}$ & 8.889 & 4.328 & 9.340 \\
\hline \multirow{2}{*}{$\begin{array}{c}\text { Countries examined } \\
\text { developed } \\
\text { developing and } \\
\text { transition }\end{array}$} & equals 1 if the researcher only examines OECD countries & 0.336 & 0.473 & 0.366 \\
\hline & equals 1 if the researcher only examines non-OECD countries & 0.324 & 0.469 & 0.376 \\
\hline
\end{tabular}




\begin{tabular}{|c|c|c|c|c|}
\hline \multirow{2}{*}{\multicolumn{5}{|c|}{ Design of the analysis }} \\
\hline & & & & \\
\hline quadratic & $\begin{array}{l}\text { equals } 1 \text { if the square of the competition coefficient is included in } \\
\text { the regression }\end{array}$ & 0.119 & 0.324 & 0.217 \\
\hline endogeneity & equals 1 if the estimation method accounts for endogeneity & 0.635 & 0.482 & 0.713 \\
\hline macro & $\begin{array}{l}\text { equals } 1 \text { if the competition-stability regression is estimated using } \\
\text { country-level data }\end{array}$ & 0.256 & 0.437 & 0.133 \\
\hline averaged & $\begin{array}{l}\text { equals } 1 \text { if the competition-stability regression uses variables in the } \\
\text { form of country-level averages over banks }\end{array}$ & 0.120 & 0.326 & 0.085 \\
\hline Treatment of stabils & & & & \\
\hline dummies & $\begin{array}{l}\text { equals } 1 \text { if stability is measured by a crisis dummy or a bank } \\
\text { failure dummy }\end{array}$ & 0.142 & 0.349 & 0.129 \\
\hline NPL & $\begin{array}{l}\text { equals } 1 \text { if stability is measured by non-performing loans as a share } \\
\text { of total loans }\end{array}$ & 0.050 & 0.218 & 0.095 \\
\hline Zscol & tability is measured by the Z-score statistic & 0.452 & 0.498 & 0.537 \\
\hline pro & ROE volatility & 0.075 & 0.264 & 0.039 \\
\hline profitability & equals $1 \mathrm{i}$ & 0.043 & 0.204 & 0.045 \\
\hline capitalization & $\begin{array}{l}\text { equals } 1 \text { if stability is measured by the capital adequacy ratio } \\
\text { (CAR) or the equity-total assets ratio }\end{array}$ & 0.069 & 0.253 & 0.040 \\
\hline DtoD & $\begin{array}{l}\text { equals } 1 \text { if stability is measured by Logistic R2 Merton's distance- } \\
\text { to-default or probability of bankruptcy }\end{array}$ & 0.065 & 0.247 & 0.047 \\
\hline & tition & & & \\
\hline & equ & 0.090 & 0.287 & 0.098 \\
\hline Boone & dicator & 0.075 & 0.264 & 0.108 \\
\hline Concentration & $\begin{array}{l}\text { equals } 1 \text { if competition is measured by concentration measures } \mathrm{C} 3 \\
\text { or } \mathrm{C} 5\end{array}$ & 0.157 & 0.364 & 0.147 \\
\hline Lerner & equals 1 if competition is measured by the Lerner index & 0.360 & 0.480 & 0.414 \\
\hline HHI & $\begin{array}{l}\text { equals } 1 \text { if competition is measured by the Herfindahl-Hirschman } \\
\text { index }\end{array}$ & 0.266 & 0.442 & 0.197 \\
\hline Estimatio & & & & \\
\hline Logit & $\begin{array}{l}\text { equals } 1 \text { if the logit or probit model is used in the estimation of } \\
\text { the competition-stability regression }\end{array}$ & .172 & 0.378 & .161 \\
\hline OI & equa & 37 & & 0.115 \\
\hline $\mathrm{F}$ & 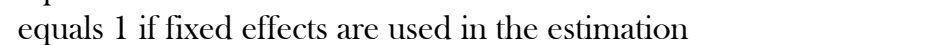 & 0.229 & 21 & 0.136 \\
\hline & tion & & & 0.043 \\
\hline GMM & & & & 0.309 \\
\hline TSLS & equals 1 if $\mathrm{t}$ & 0.149 & 0.356 & 0.110 \\
\hline Control variables & & & & \\
\hline regulation & $\begin{array}{l}\text { equals } 1 \text { if regulatory/supervisory variables are included in the } \\
\text { competition-stability regression }\end{array}$ & 0.239 & 0.427 & 0.282 \\
\hline ownership & $\begin{array}{l}\text { equals } 1 \text { if bank ownership is controlled for in the competition- } \\
\text { stability regression }\end{array}$ & 0.166 & 0.372 & 0.271 \\
\hline global & $\begin{array}{l}\text { equals } 1 \text { if macroeconomic variables are included in the } \\
\text { competition-stability regression }\end{array}$ & 0.794 & 0.405 & 0.764 \\
\hline a & ristics & & & \\
\hline citations & $\begin{array}{l}\text { The logarithm of the number of Google Scholar citations } \\
\text { normalized by the difference between } 2015 \text { and the year the study } \\
\text { first appeared in Google Scholar (collected in July 2014) }\end{array}$ & 2.045 & 1.222 & 1.790 \\
\hline firstpub & $\begin{array}{l}\text { The year when the study first appeared in Google Scholar (base: } \\
\text { 2003) }\end{array}$ & 6.453 & 2.979 & 6.677 \\
\hline IFrecursive & $\begin{array}{l}\text { The recursive impact factor of the outlet from RePEc (collected in } \\
\text { July 2014) }\end{array}$ & 3 & 0.210 & 0.205 \\
\hline reviewed_journal & equals 1 if the study is published in a peer-reviewed journal & 0.629 & 0.484 & 0.677 \\
\hline
\end{tabular}

Notes: SD = standard deviation. $\mathrm{WM}=$ mean weighted by the inverse of the number of estimates reported per study. All variables except for citations and the impact factor are collected from studies estimating the competition coefficient from equation (1). The search for studies was terminated on July 1, 2014, and the list of studies included is available in Appendix B. Citations are collected from Google Scholar and the impact factor from RePEc. 
Group 1 - Data characteristics: We control for the age of the data used in the primary studies by including the variable sampleyear, which represents the midpoint of the data period used by researchers. Moreover, we account for the number of cross-sectional units used to estimate the competition coefficient in equation (1) and for the number of time periods used in the estimation. The underlying reasoning is that, ceteris paribus, one would like to place more weight on studies using larger samples, and it is therefore important to check whether such studies yield systematically different results.

Group 2 - Countries examined: As the estimates of the competition coefficient may have different size and signs for different countries or blocks of countries, we control for this potential source of heterogeneity by including dummies for developed (OECD member) countries and developing and transition (non-OECD) countries. In our sample, $34 \%$ of all the collected estimates are obtained using a sample of developed countries, while $32 \%$ of estimates are extracted from studies focusing on developing and transition countries. The remaining third of studies mix these two groups of countries in their estimations.

Group 3 - Design of the analysis: We control for specific aspects of the studies in our sample, captured by the variables endogeneity, macro, quadratic, and averaged. The dummy variable endogeneity reflects whether individual studies account for potential endogeneity in their analysis, either via econometric methods or by using lagged values of variables in equation (1). The dummy variable macro assigns the value 1 to an estimate if the estimate is calculated using data constructed at the aggregate level, as opposed to studies using bank-level data. Next, the dummy variable averaged assigns the value 1 to an estimate if the regressors in equation (1) in the original study are constructed as country-level averages over banks, even though the data are technically bank-level. Finally, the dummy variable quadratic controls for the inclusion of the square of the competition measure in the regressions. In total, $12 \%$ of the estimates in our sample have to be linearized because researchers test for possible nonlinear relationships between bank competition and stability.

Group 4 - Treatment of stability: We control for differences in the way stability is measured in individual studies. Due to the large diversity of the approaches to measuring financial stability in the literature, it is possible that a substantial portion of the variation in the competition coefficient estimates is due to a different definition of stability. We distinguish the seven most common approaches. Some researchers use dummy variables representing either the outbreak of a systemic banking crisis or a bank failure (e.g. Beck et al., 2006 a,b; Fungacova and Weill, 2009). Popular methods for measuring individual bank stability include the ratio of nonperforming loans to total bank loans, the return on assets (ROA) or return on equity (ROE) as measures of bank profitability, fluctuations in ROA or ROE as indicators of bank profit volatility, the Z-score, an aggregate measure of bank stability, measures of capitalization, the capital adequacy ratio or equity to assets ratio, and measures of distance to default.

Group 5 - Treatment of competition: Similarly to the indicators of stability, there is large diversity in the approaches to quantifying competition within the banking sector. We control for the five most commonly used measures. For $36 \%$ of the estimates in our sample, competition is measured via the Lerner index. Other indicators include Panzar and Rosse's (1987) H-statistic and Boone's (2008) Boone index. Quite frequently, measures of market structure are applied 
to assess the intensity of competition in the sector, such as concentration ratios and HerfindahlHirschman indices (HHI), which are used to compute $42 \%$ of the estimates in the sample (e.g., by Beck et al., 2006 a,b; Berger et al., 2009; Boyd et al., 2006; Cipollini and Fiordelisi, 2009). We decide to include the estimates arising from the use of these market structure measures in our analysis despite the recent assertions in the literature that concentration is not a suitable proxy for a lack of competition (e.g. Claessens and Laeven, 2004; Bikker, 2004). As a robustness check in Section 6, we estimate the impact of competition on stability after excluding these potentially misspecified estimates from our sample.

Group 6 - Estimation methods: We control for six different estimation methods in our analysis: OLS, FE, RE, GMM, TSLS, and logit. We assume that different approaches to estimating equation (1) might affect the resulting estimates of the competition coefficient. The most frequently used estimation methods in our sample are fixed effects (23\% of estimates), followed by GMM (18\%) and logit (17\%). In our data set the variable reflecting the use of logit is not identical to the variable that captures the use of dummy variables on the left-hand side, because some of the studies that employ dummy variables use linear estimation techniques. Moreover, other studies, e.g. Cipollini and Fiordelisi (2009), incorporate either random effects or GMM estimators into logit and probit models, which we in turn classify into the RE or GMM categories.

Group 7 - Control variables: The most commonly used controls in the estimation of the competition-stability relationship in equation (1) are macroeconomic variables defined at the country level, regulatory and supervisory variables such as capital stringency, supervisory power, the investor protection index, economic and banking freedom, the share of market entry restrictions or governance (e.g. Cihak et al., 2009; Beck et al., 2006 a,b; Beck et al., 2013; Anginer et al., 2014; Agoraki et al., 2011), and ownership controls, i.e., foreign and state bank ownership (e.g. Bazzana and Yaldiz, 2010; Berger et al., 2009; De Nicolò and Loukoianova, 2007). Macroeconomic variables are used as controls in $79 \%$ of regressions, while regulatory and supervisory controls are used in $24 \%$ of regressions and ownership variables in $17 \%$ of regressions.

Group 8 - Publication characteristics: In order to evaluate whether studies published in peerreviewed journals report systematically different estimates in comparison to unpublished studies after we control for data and methodology, we include a corresponding dummy variable. Moreover, we control for study quality by including the number of citations and the recursive RePEc impact factor. Finally, for each study we add the year when it first appeared in Google Scholar to control for the potential time trend in the literature.

We would like to run a regression with the PCC of the estimates of the competition coefficient as the dependent variable and all the variables introduced above as explanatory variables. Nevertheless, including all of the variables at the same time is infeasible as we would probably obtain many redundant regressors in the specification. With such a large number of explanatory variables, we initially do not know which ones should be excluded from the model. An ideal approach would be to run regressions with different subsets of independent variables to ensure that our results are robust: to this end, we employ Bayesian model averaging (BMA) to resolve 
the model uncertainty problem, an issue that is inevitable in meta-regression analysis. BMA runs many regressions with different subsets of all the $2^{35}$ possible combinations of explanatory variables (we have 35 regressors at our disposal). To make the estimation feasible, we employ the Monte Carlo Markov Chain algorithm to go through the most promising of the potential models (we use the bms package for $\mathrm{R}$ developed by Feldkircher and Zeugner, 2009). BMA gives each model a weight, which can be thought of as an analogy of the adjusted R-squared, to capture the model's fit. Finally, BMA reports weighted averages from the models for posterior mean values of regression parameters and posterior standard deviations, which capture the distribution of regression parameters across individual models. Moreover, a posterior inclusion probability (PIP) is reported for each variable to show the probability with which the variable is included in the true model. Raftery et al. (1997) and Eicher et al. (2011) provide further details on BMA in general. Detailed diagnostics of our BMA exercise can be found in Appendix A.

Figure 5: Bayesian model averaging - model inclusion

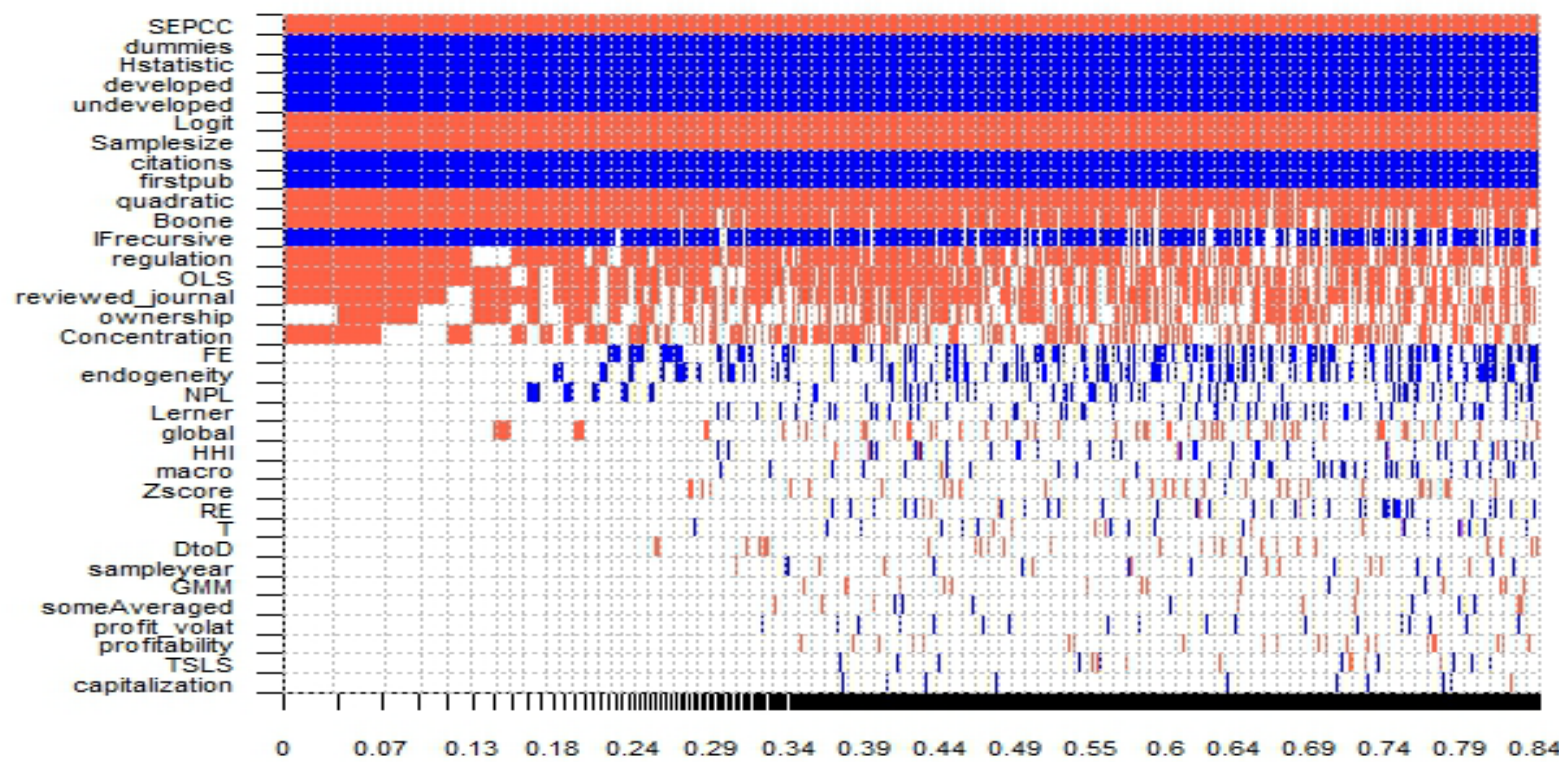

Cumulative Model Probabilities

Notes: The response variable is the PCC of the estimate of the competition coefficient (the PCC of the $\beta$ estimate from equation (1)). All regressions are weighted by the inverse of the number of estimates reported per study. Columns denote individual models; the variables are sorted by posterior inclusion probability in descending order. Blue color (darker in grayscale) $=$ the variable is included and the estimated sign is positive. Red color (lighter in grayscale) $=$ the variable is included and the estimated sign is negative. No color $=$ the variable is not included in the model. The horizontal axis measures the cumulative posterior model probabilities. Numerical results of the BMA estimation are reported in Table 5. A detailed description of all the variables is available in Table 4 .

\subsection{Results}

Figure 5 shows the results of the BMA exercise. The columns in the figure denote the individual regression models, while their width indicates the models' posterior probabilities. The variables are sorted by their PIP in descending order. If the sign of a variable's regression coefficient is positive, it is denoted by blue color (darker in grayscale). Conversely, if the sign of 
a variable's coefficient is negative, it is colored in red. Where a variable is excluded from a model, the corresponding cell is left blank. The horizontal axis measures the cumulative model probabilities: the models that are the most successful in explaining the heterogeneity in the estimates of the competition effect are on the left, and we can see that they include less than a half of all the variables.

The numerical results of the BMA exercise are reported in Table 5. On the right-hand side of the table we also report the results of OLS estimation with standard errors clustered at the level of individual studies. From this "frequentist check" we exclude the variables that prove to be irrelevant for the explanation of the variability in the literature (that is, have PIP lower than 0.5). The OLS regression thus includes 15 variables identified by BMA to help explain the variation in the reported competition effects. Overall, OLS with clustered standard errors yields results consistent with BMA for variables with high inclusion probabilities. The signs of the variables' regression parameters are the same and the size of their parameter estimates is similar as well. Therefore, we can conclude that our results are robust to error-clustering, as BMA by definition does not cluster standard errors in the estimation. Eicher et al. (2011) provide a framework for the identification of the strength of the variables' effect in BMA. The effect of a variable is considered weak if the corresponding PIP is between 0.5 and 0.75 , substantial if it is between 0.75 and 0.95 , strong if it is between 0.95 and 0.99 , and decisive if it exceeds 0.99 .

Table 5: Explaining heterogeneity in the estimates of the competition coefficient

\begin{tabular}{|c|c|c|c|c|c|c|}
\hline \multirow{2}{*}{$\begin{array}{l}\text { Response variable: } \\
\text { Competition effect }\end{array}$} & \multicolumn{3}{|c|}{ Bayesian model averaging } & \multicolumn{3}{|c|}{ Frequentist check (OLS) } \\
\hline & Post. Mean & Post. SD & PIP & Coef. & $\begin{array}{l}\text { Robust } \\
\text { Std. Err. }\end{array}$ & P-value \\
\hline \multicolumn{7}{|l|}{ Data characteristics } \\
\hline SEPCC & -1.7883 & 0.2046 & 1.0000 & -1.1940 & 0.6511 & 0.067 \\
\hline Samplesize & -0.0367 & 0.0035 & 1.0000 & -0.0240 & 0.0089 & 0.007 \\
\hline $\mathrm{T}$ & 0.0005 & 0.0039 & 0.0517 & & & \\
\hline sampleyear & 0.0000 & 0.0005 & 0.0456 & & & \\
\hline $\begin{array}{l}\text { Countries examined } \\
\text { developed }\end{array}$ & \multicolumn{5}{|c|}{ Countries examined } & 0.000 \\
\hline developing and transition & 0.1072 & 0.0169 & 1.0000 & 0.0985 & 0.0262 & 0.000 \\
\hline \multicolumn{7}{|l|}{ Design of the analysis } \\
\hline quadratic & -0.0533 & 0.0124 & 0.9971 & -0.0441 & 0.0128 & 0.001 \\
\hline endogeneity & 0.0100 & 0.0212 & 0.2371 & & & \\
\hline macro & 0.0025 & 0.0124 & 0.0699 & & & \\
\hline someAveraged & -0.0004 & 0.0047 & 0.0397 & & & \\
\hline \multicolumn{7}{|l|}{ Treatment of stability } \\
\hline dummies & 0.2115 & 0.0282 & 1.0000 & 0.1841 & 0.0194 & 0.000 \\
\hline NPL & 0.0020 & 0.0060 & 0.1323 & & & \\
\hline Zscore & -0.0005 & 0.0027 & 0.0630 & & & \\
\hline profit_volat & 0.0006 & 0.0051 & 0.0371 & & & \\
\hline profitability & -0.0003 & 0.0030 & 0.0354 & & & \\
\hline capitalization & 0.0001 & 0.0029 & 0.0271 & & & \\
\hline DtoD & -0.0013 & 0.0078 & 0.0504 & & & \\
\hline \multicolumn{7}{|l|}{ Treatment of competition } \\
\hline Hstatistic & 0.1083 & 0.0217 & 1.0000 & 0.1140 & 0.0181 & 0.000 \\
\hline Boone & -0.0709 & 0.0313 & 0.8974 & -0.0583 & 0.0225 & 0.010 \\
\hline Concentration & -0.0185 & 0.0226 & 0.4742 & & & \\
\hline Lerner & 0.0036 & 0.0130 & 0.1217 & & & \\
\hline $\mathrm{HHI}$ & 0.0023 & 0.0108 & 0.0847 & & & \\
\hline
\end{tabular}




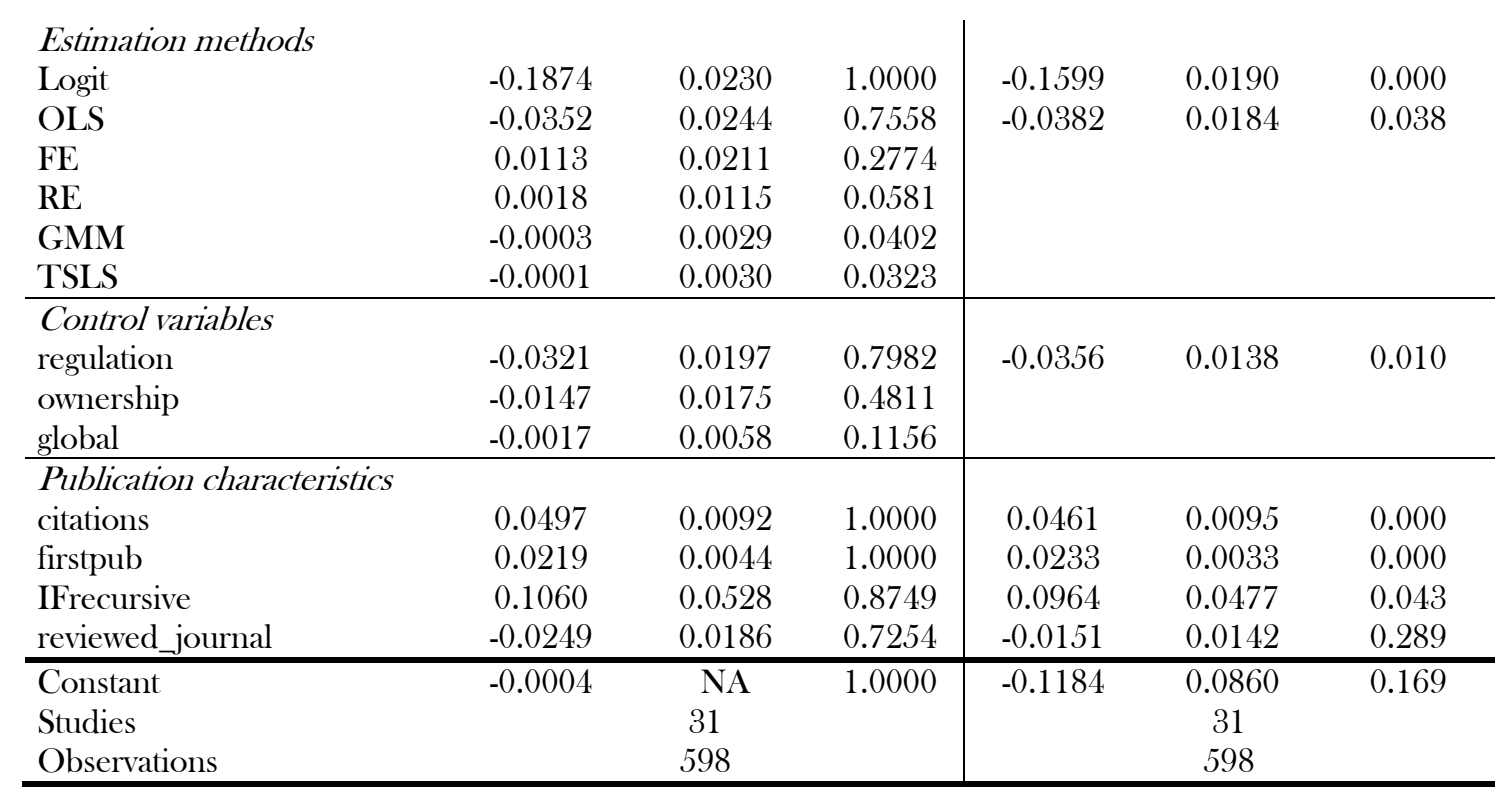

Notes: The response variable of the PCC of the $\beta$ estimate from equation (1). PIP $=$ posterior inclusion probability. Post. SD = posterior standard deviation. In the frequentist check we only include explanatory variables with PIP $>0.5$. The standard errors in the frequentist check are clustered at the study level. More details on the BMA estimation are available in Table A1 and Figure A1. A detailed description of all the variables can be found in Table 4 .

The results of our BMA exercise support the notion of the presence of publication bias (the regression coefficient on the standard error is similar to the one presented in Section 4); it seems that positive and insignificant estimates are underreported in the literature, because researchers tend to prefer results that are consistent with the competition-fragility hypothesis. Next, the larger the size of the data sample, the smaller the reported coefficient appears to be. As for country coverage, it seems that the estimates for developed countries tend to be slightly larger than those for non-OECD countries. The use of a quadratic relationship between competition and financial stability is associated with estimates that are on average 0.05 smaller, and the corresponding variable has a decisive posterior inclusion probability.

When financial stability is proxied by dummy variables for financial distress, the resulting competition coefficient estimates tend to be inflated by 0.21 . In contrast, the use of macro data does not affect the reported results in a systematic way. This finding is at odds with the literature survey by Beck (2008, p. 6), who notes that "while bank-level studies do not provide unambiguous findings on the relationship between competition and stability, cross-country studies point mostly to a positive relationship.” Similarly, our results contrast the finding by Schaeck and Cihak (2012), who argue that banks have higher capital ratios in more competitive environments, and thus that capitalization is one of the channels through which competition enhances stability. On the contrary, after controlling for many other method choices, we find that the use of capitalization as a proxy for stability does not affect the reported estimates of the effect of competition on stability.

As for the measures of competition, the reported estimates tend to be larger by 0.11 when Panzar and Rosse's (1987) H-statistic is used to measure bank competition. This systematic measurement issue could be due to the fact that the $\mathrm{H}$-statistic imposes restrictive assumptions on a bank's cost function that are only valid when the market in question is in equilibrium 
(Beck, 2008). When competition is measured by the Boone index, the estimations yield smaller effects on stability (by 0.05) and the explanatory power of this variable measured by the PIP is substantial. Concerning the suitability of market structure measures of competition, i.e., concentration ratios and HHI, neither of these measures was selected in our BMA exercise as useful in explaining the variation in the literature. To further check the robustness of this result, we repeat the BMA analysis in Section 6 after excluding coefficient estimates obtained from regressions where competition was proxied by measures of concentration and HHI.

Regarding estimation methods, our results suggest that estimating equation (1) by a logit or a probit model tends to decrease the competition coefficient estimates by 0.19 , while estimation by ordinary least squares (therefore, ignoring potential endogeneity) causes a moderate downward bias of about 0.04 . Controlling for regulatory and supervisory measures decreases the estimated coefficient by approximately 0.03 , which is in line with the arguments raised by Barth, Caprio, and Levine (2004) and Beck et al. (2006 a,b).

All publication characteristics that we control for have relatively high posterior inclusion probabilities. A higher recursive impact factor and more study citations are associated with larger reported estimates. Conversely, peer-reviewed journals seem to publish estimates 0.02 smaller than those reported in unpublished manuscripts, though the inclusion probability for this variable suggests only a weak effect. Moreover, our results indicate that the reported estimates of the competition coefficient increase over time.

As a final step of our analysis, we attempt to calculate the mean estimate of the competitionstability nexus after correcting for potential misspecifications and placing greater weight on estimates published in quality outlets. This part of our analysis is the most subjective as it requires a definition of "best practice" in estimating the competition coefficient. For each variable deemed useful by the BMA exercise, i.e., with PIP larger than 0.5 , we plug in a preferred value, a sample minimum or a sample maximum, or, in the case of no preference, a sample mean. Then we compute a linear combination of regression parameters and obtain the value of the partial correlation coefficient conditional on our definition of best practice. We plug in the sample maxima for the size of the data set, the recursive impact factor, and the number of citations. We also prefer if the study is published in a peer-reviewed journal, if the estimation controls for regulation measures, as a higher degree of restrictions on banks' activities and barriers to bank entry is linked to systemic banking distress (Barth, Caprio, and Levine, 2004; Beck et al., 2006 a,b), and if the researcher uses the Boone index, a relatively novel approach to measuring competition arising from the industrial organization literature.

Because our focus rests primarily on the most precise competition coefficient estimates, we plug in the value 0 for the standard error of the PCC of the estimate (similarly as in Section 4, this approach corrects for publication bias). We also prefer if OLS is not used for the estimation of the competition-stability nexus, because it does not account for potential endogeneity. We prefer if a continuous variable is used as a proxy for stability, and if simple logit is not used for the estimation (again, because it does not allow for addressing endogeneity). We plug in zero for the dummy variable that corresponds to the assumed quadratic relation between competition and stability; in this case we have to linearize the estimates, which might induce a bias. We prefer if the H-statistic is not used in the estimation, because, as we have mentioned, it 
imposes restrictive assumptions on a bank's cost function that are only valid when the market in question is in equilibrium (Beck, 2008). We plug in sample means for all the other variables.

Table 6: Best-practice estimates of the competition coefficient

\begin{tabular}{l|cccc|cccc}
\multirow{2}{*}{ Best practice } & \multicolumn{4}{|c|}{ Weighted } & \multicolumn{4}{c}{ Unweighted } \\
\cline { 2 - 8 } & Estimate & 95\% Conf. Int. & Diff. & Estimate & $95 \%$ Conf. Int. & Diff. \\
\hline All countries & 0.022 & -0.022 & 0.066 & 0.034 & 0.038 & 0.000 & 0.076 & 0.039 \\
$\begin{array}{l}\text { Developed } \\
\begin{array}{l}\text { Developing and } \\
\text { transition }\end{array}\end{array}$ & 0.096 & 0.049 & 0.144 & 0.085 & 0.091 & 0.045 & 0.137 & 0.071 \\
\hline
\end{tabular}

Notes: The table presents estimates of the competition coefficient for selected country groups implied by Bayesian model averaging and our definition of best practice. We take the regression coefficients estimated by BMA with PIP > 0.5 and construct fitted values of the competition coefficient conditional on control for publication characteristics and other aspects of methodology (see the text for details). Diff. $=$ the difference between these estimates and the means reported in Table 1. The confidence intervals are constructed using study-level clustered standard errors estimated by OLS. The right-hand part of the table presents results based on the robustness check using unweighted regressions (Table 8 in the next section).

Table 6 summarizes the results of our best-practice estimation. Apart from the baseline results reported in the left-hand part of the table, we also report results for unweighted regressions (discussed in more detail in the next section) in the right-hand part. The column denoted "Diff." shows the difference between the best-practice coefficient estimates and the simple means of the reported coefficients presented in Table 1 for all countries, developed countries, and developing and transition countries. In general, all the best-practice coefficient estimates are larger than the means reported in Table 1, which captures both the correction for publication bias and alleged misspecifications. Concerning the baseline results, however, only the estimate for developed countries is positive and statistically significant at the $5 \%$ level. Nevertheless, based on the guidelines for the interpretation of the size of partial correlation coefficients in economics (Doucouliagos, 2011), even the largest estimate reported in Table 6 represents merely a borderline case between no effect and a small effect. According to the classic Cohen (1988) guidelines, the estimate is below the threshold set for small effects. Overall, even the best-practice exercise does not reveal any important effect of bank competition on financial stability.

\section{Robustness Checks}

\subsection{Alternative BMA Specifications}

In this subsection we present the results of two robustness checks, which we obtain by estimating the BMA exercise with some modifications. First, we report the results of BMA when employing alternative priors (g-prior and model size). Second, we present the results for unweighted regressions with the same priors for BMA as in the baseline estimation in Section 5 . 
The baseline estimation presented in the previous section employs the unit information prior for Zellner's g-prior. In this setting, the prior contains the same amount of information as one observation in the data set, and the prior is commonly used in the literature. Moreover, the uniform model prior used in the baseline specification gives the same prior probability to each model; Eicher et al. (2011) show that their choice of priors often delivers the best predictive performance. Nevertheless, the uniform model prior favors models with the mean number of regressors, i.e., $35 / 2=17.5$, because they are the most numerous among all the possible model combinations. Therefore, our first alternative specification uses a beta-binomial prior that places the same probability on each model size, in contrast to each model (Ley and Steel, 2009). We accompany the beta-binomial model prior with the BRIC g-prior as in Fernandez et al. (2001).

Table 7 presents the results of our BMA exercise with alternative priors. The results are qualitatively as well as quantitatively very similar to those of the baseline specification. We observe no significant differences in the magnitude of the posterior means of individual variables, and the same statement holds for their posterior inclusion probabilities. The subset of regressors identified as useful (with PIP above 0.5) fully coincides with that of the baseline specification.

Table 7: Results with alternative BMA priors

\begin{tabular}{|c|c|c|c|c|c|c|}
\hline \multirow{2}{*}{$\begin{array}{l}\text { Response variable: } \\
\text { Competition effect }\end{array}$} & \multicolumn{3}{|c|}{ Bayesian model averaging } & \multicolumn{3}{|c|}{ Frequentist check (OLS) } \\
\hline & Post. Mean & Post. SD & PIP & Coef. & $\begin{array}{l}\text { Robust } \\
\text { Std. Err. }\end{array}$ & P-value \\
\hline \multicolumn{7}{|l|}{ Data characteristics } \\
\hline SEPCC & -1.7527 & 0.2120 & 1.0000 & -1.1940 & 0.6511 & 0.067 \\
\hline Samplesize & -0.0362 & 0.0036 & 1.0000 & -0.0240 & 0.0089 & 0.007 \\
\hline $\mathrm{T}$ & 0.0003 & 0.0034 & 0.0373 & & & \\
\hline sampleyear & 0.0000 & 0.0005 & 0.0335 & & & \\
\hline \multicolumn{6}{|l|}{ Countries examined } & 0.000 \\
\hline developing and transition & 0.1030 & 0.0188 & 1.0000 & 0.0985 & 0.0262 & 0.000 \\
\hline \multicolumn{7}{|l|}{ Design of the analysis } \\
\hline quadratic & -0.0517 & 0.0141 & 0.9884 & -0.0441 & 0.0128 & 0.001 \\
\hline endogeneity & 0.0159 & 0.0269 & 0.3037 & & & \\
\hline macro & 0.0028 & 0.0132 & 0.0672 & & & \\
\hline Averaged & -0.0004 & 0.0043 & 0.0310 & & & \\
\hline \multicolumn{7}{|l|}{ Treatment of stability } \\
\hline dummies & 0.2179 & 0.0315 & 1.0000 & 0.1841 & 0.0194 & 0.000 \\
\hline NPL & 0.0012 & 0.0047 & 0.0818 & & & \\
\hline Zscore & -0.0004 & 0.0023 & 0.0427 & & & \\
\hline profit_volat & 0.0004 & 0.0043 & 0.0255 & & & \\
\hline profitability & -0.0002 & 0.0024 & 0.0236 & & & \\
\hline capitalization & 0.0001 & 0.0024 & 0.0186 & & & \\
\hline DtoD & -0.0007 & 0.0060 & 0.0313 & & & \\
\hline \multicolumn{7}{|l|}{ Treatment of competition } \\
\hline Hstatistic & 0.1074 & 0.0228 & 1.0000 & 0.1140 & 0.0181 & 0.000 \\
\hline Boone & -0.0637 & 0.0375 & 0.8020 & -0.0583 & 0.0225 & 0.010 \\
\hline Concentration & -0.0182 & 0.0244 & 0.4183 & & & \\
\hline Lerner & 0.0032 & 0.0128 & 0.0946 & & & \\
\hline $\mathrm{HHI}$ & 0.0021 & 0.0107 & 0.0659 & & & \\
\hline \multicolumn{7}{|l|}{ Estimation methods } \\
\hline Logit & -0.1883 & 0.0237 & 1.0000 & -0.1599 & 0.0190 & 0.000 \\
\hline
\end{tabular}




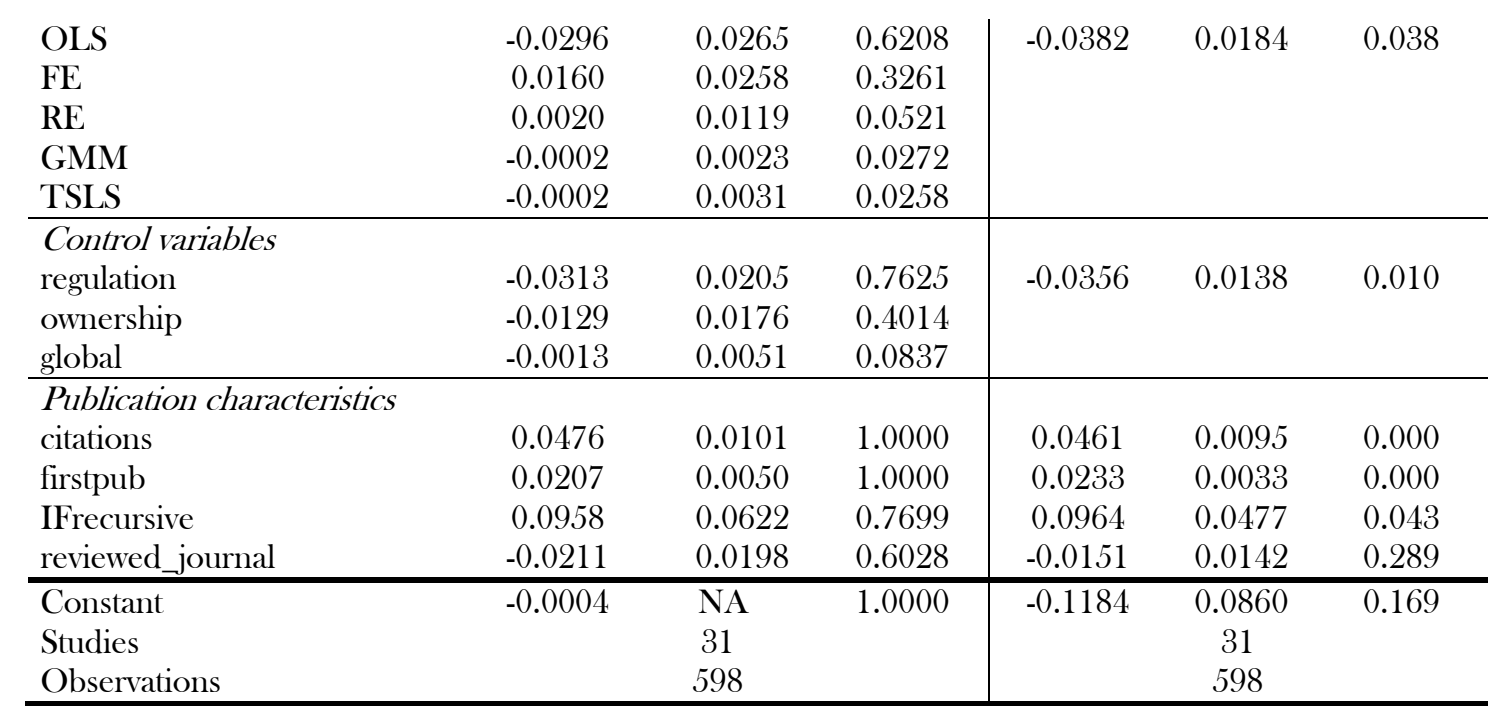

Notes: The response variable is the competition effect. PIP $=$ posterior inclusion probability. SD = standard deviation. In the frequentist check we only include explanatory variables with PIP $>0.5$. The standard errors in the frequentist check are clustered at the study level. In this specification we use the beta-binomial prior advocated by Ley \& Steel (2009) (the prior model probabilities are the same for all model sizes) and the BRIC g-prior following Fernandez et al. (2001). More details on the BMA estimation are available in Table A2 in Appendix A. A detailed description of all the variables is available in Table 4.

Second, we run the BMA exercise with the same priors as in our baseline specification but for regressions not weighted by the inverse of the number of observations reported in studies. In this case studies with fewer reported competition coefficient estimates become less influential in the meta-analysis, and the results are dominated by papers that produce many estimates. In this robustness check the BMA only selects 14 variables with inclusion probability higher than 0.5 as opposed to 15 variables in the baseline specification. In addition, the results of the robustness check suggest that measuring stability by means of bank profitability tends to lower the coefficient estimate by 0.03 . In contrast, estimating equation (1) by fixed effects or instrumental variables increases the estimated competition coefficient by 0.05 , with a decisive PIP in both cases. These findings are consistent with our results from the previous section, where we report that using OLS (which disregards endogeneity) is associated with smaller reported estimates.

Furthermore, including controls for bank ownership decreases the reported estimate by 0.06 with a decisive PIP. This finding supports the results by Barth, Caprio, and Levine (2004), who argue that bank ownership matters for bank stability. In particular, they find that foreign bank entry tends to be positively related to banking system stability, while government ownership impacts competitiveness as well as stability in a negative way. In contrast to the baseline specification, here we do not find the following aspects important: controlling for a nonlinear relationship between competition and stability, measuring competition via the Boone index, estimating equation (1) by means of OLS, controlling for regulation and supervision in the banking sector, and publication of the study in a peer-reviewed journal. As for the signs and magnitudes of the estimated coefficients for individual regressors, they broadly coincide with the baseline specification. Nevertheless, the robustness check shows less evidence for publication bias in the literature. Also, the estimated coefficients for dummy variables reflecting developed 
and developing countries are much smaller, shrinking the difference between the implied competition coefficients for the different country groups.

Table 8: Results for unweighted regressions

\begin{tabular}{|c|c|c|c|c|c|c|}
\hline \multirow{2}{*}{$\begin{array}{l}\text { Response variable: } \\
\text { Competition effect }\end{array}$} & \multicolumn{3}{|c|}{ Bayesian model averaging } & \multicolumn{3}{|c|}{ Frequentist check (OLS) } \\
\hline & Post. Mean & Post. SD & PIP & Coef. & $\begin{array}{l}\text { Robust } \\
\text { Std. Err. }\end{array}$ & P-value \\
\hline \multicolumn{7}{|l|}{ Data characteristics } \\
\hline SEPCC & -0.7259 & 0.5667 & 0.7003 & -0.5768 & 0.7862 & 0.4630 \\
\hline Samplesize & -0.0258 & 0.0082 & 1.0000 & -0.0248 & 0.0092 & 0.0070 \\
\hline $\mathrm{T}$ & 0.0008 & 0.0034 & 0.0735 & & & \\
\hline sampleyear & 0.0006 & 0.0015 & 0.1946 & & & \\
\hline \multicolumn{7}{|l|}{ Countries examined } \\
\hline $\begin{array}{l}\text { developed } \\
\text { developing and transition }\end{array}$ & $\begin{array}{l}0.1529 \\
0.1127\end{array}$ & $\begin{array}{l}0.0172 \\
0.0172\end{array}$ & $\begin{array}{l}1.00(0) \\
1.0000\end{array}$ & $\begin{array}{l}0.1519 \\
0.1156\end{array}$ & $\begin{array}{l}0.0175 \\
0.0170\end{array}$ & $\begin{array}{l}0.0000 \\
0.0000\end{array}$ \\
\hline \multicolumn{7}{|l|}{ Design of the analysis } \\
\hline quadratic & 0.0012 & 0.0050 & 0.0755 & & & \\
\hline endogeneity & 0.0056 & 0.0110 & 0.2461 & & & \\
\hline macro & -0.0103 & 0.0161 & 0.3408 & & & \\
\hline Averaged & 0.0000 & 0.0024 & 0.0219 & & & \\
\hline \multicolumn{7}{|l|}{ Treatment of stability } \\
\hline dummies & 0.1861 & 0.0281 & 1.0000 & 0.1660 & 0.0176 & 0.0000 \\
\hline NPL & 0.0138 & 0.0249 & 0.2739 & & & \\
\hline Zscore & 0.0091 & 0.0166 & 0.2660 & & & \\
\hline profit_volat & 0.0176 & 0.0238 & 0.4350 & & & \\
\hline profitability & -0.0281 & 0.0233 & 0.6587 & -0.0451 & 0.0246 & 0.0660 \\
\hline capitalization & 0.0101 & 0.0196 & 0.2437 & & & \\
\hline DtoD & -0.0015 & 0.0080 & 0.0674 & & & \\
\hline \multicolumn{7}{|l|}{ Treatment of competition } \\
\hline Hstatistic & 0.1294 & 0.0223 & 1.0000 & 0.1123 & 0.0173 & 0.0000 \\
\hline Boone & -0.0021 & 0.0088 & 0.0873 & & & \\
\hline Concentration & 0.0159 & 0.0244 & 0.3626 & & & \\
\hline Lerner & 0.0136 & 0.0211 & 0.3566 & & & \\
\hline HHI & 0.0103 & 0.0199 & 0.2488 & & & \\
\hline \multicolumn{7}{|l|}{ Estimation methods } \\
\hline Logit & -0.1304 & 0.0303 & 0.9999 & -0.1275 & 0.0121 & 0.0000 \\
\hline OLS & 0.0000 & 0.0019 & 0.0214 & & & \\
\hline FE & 0.0621 & 0.0134 & 1.0000 & 0.0503 & 0.0113 & 0.0000 \\
\hline $\mathrm{RE}$ & 0.0128 & 0.0204 & 0.3355 & & & \\
\hline GMM & 0.0000 & 0.0018 & 0.0221 & & & \\
\hline TSLS & 0.0532 & 0.0132 & 0.9999 & 0.0515 & 0.0147 & 0.0000 \\
\hline \multicolumn{7}{|l|}{ Control variables } \\
\hline regulation & 0.0002 & 0.0020 & 0.0281 & & & \\
\hline ownership & -0.0595 & 0.0096 & 1.0000 & -0.0588 & 0.0289 & 0.0420 \\
\hline global & 0.0016 & 0.0054 & 0.1033 & & & \\
\hline \multicolumn{7}{|l|}{ Publication characteristics } \\
\hline citations & 0.0377 & 0.0063 & 0.9996 & 0.0407 & 0.0087 & 0.0000 \\
\hline firstpub & 0.0179 & 0.0033 & 0.9997 & 0.0205 & 0.0029 & 0.0000 \\
\hline IFrecursive & 0.0470 & 0.0419 & 0.6405 & 0.0490 & 0.0379 & 0.1960 \\
\hline reviewed_journal & 0.0019 & 0.0080 & 0.0807 & & & \\
\hline Constant & -0.1269 & NA & 1.0000 & -0.1263 & 0.0870 & 0.1460 \\
\hline Studies & & 31 & & & 31 & \\
\hline Observations & & 598 & & & 598 & \\
\hline
\end{tabular}

Notes: The response variable is the competition effect. $\mathrm{PIP}=$ posterior inclusion probability. $\mathrm{SD}=$ standard deviation. In the frequentist check we only include explanatory variables with PIP $>0.5$. The standard errors in the frequentist check are clustered at the study level. In this specification we do not weight the regressions by the inverse of the number of estimates reported per study. More details on the BMA estimation are available in Table A3 in Appendix A. A detailed description of all the variables is available in Table 4. 


\subsection{Excluding Estimates Computed Using Concentration Measures}

In this subsection we evaluate the robustness of our results using a more homogeneous data set. We exclude the estimates in which market structure measures, such as concentration ratios and HHI, are used as proxies for competitiveness in the banking sector. There are several reasons why the estimates constructed using concentration measures might not be fully comparable to the rest of the literature. For example, Claessens and Laeven (2004) conclude that concentration is an unsuitable proxy for competition and that the two measures, concentration and competition, highlight different banking sector characteristics. Furthermore, Beck (2008, p. 17), in his literature survey, argues that "market structure measures such as concentration ratios are inadequate measures of bank competition. Higher concentration might result in more stability through channels other than lack of competitiveness, such as improved risk diversification." Therefore, a higher degree of market concentration does not necessarily imply less competition.

After excluding the concentration-stability estimates from our sample, we are left with 345 reported coefficient estimates from regressions where competition is measured by either the Lerner index, the H-statistic or the Boone index. This robustness check is extensive and has the same structure as the baseline analysis presented in the previous sections; it summarizes the new data set, tests for publication bias, and attempts to quantify the "best-practice" estimate of the competition-stability nexus. We show that the conclusions from this robustness check are similar to our main results.

Figure 6: Time evolution of estimates

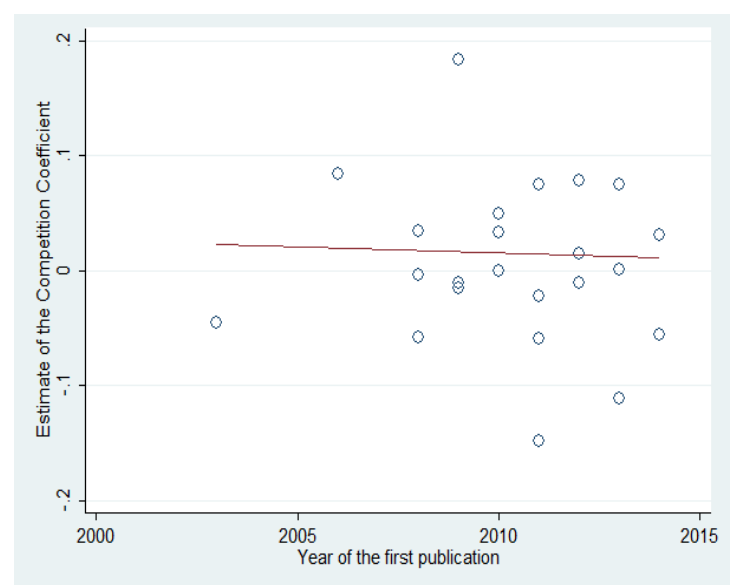

Notes: The figure depicts the median PCCs of the pure competition coefficient estimates (the PCCs of the $\beta$ estimates from equation (1)) reported in individual studies. The horizontal axis measures the year when the first drafts of studies appeared in Google Scholar. The line shows the linear fit.
Figure 7: Distribution of estimates

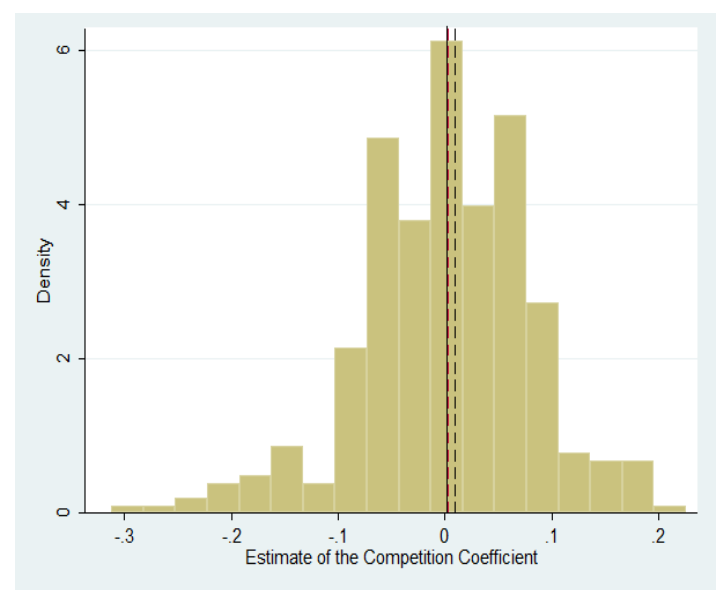

Notes: The figure shows the histogram of the PCCs of the pure competition coefficient estimates (the PCCs of the $\beta$ estimates from equation (1)) reported in individual studies. The solid vertical line denotes the mean of all the PCCs. The dashed lines denote the mean of the study-level medians and the mean of the PCCs of the estimates reported in studies published in peerreviewed journals. 
Figure 6 plots the medians of the "pure" (that is, homogeneous) competition-stability coefficient estimates against the first year of publication of the study from which they are collected. Once again we observe an increasing spread among the reported coefficient estimates over time. The slight upward trend in the reported estimates for the entire sample is now replaced by a similarly slight downward tendency.

Figure 7 displays the histogram of the PCCs of the competition estimates. The solid line depicts the mean PCC value over all studies, which equals 0.0011, while the black dashed line denotes the mean of the study-level medians (0.0104). Additionally, the red dashed line shows the mean PCC of the estimates published in journals (0.0016). In sum, these statistics are statistically insignificant in all cases, consistent with the results reported earlier for the whole sample, and imply very little impact of bank competition on financial stability.

Figure 8 depicts the partial correlation coefficients of the pure competition coefficient estimates from equation (1) as reported in individual studies. After omitting the concentration-stability coefficient estimates from the sample, the number of individual studies decreases from 31 in the original sample to 23 . The more homogeneous sample shows similar values of within- and between-study heterogeneity in the reported results.

Figure 8: Estimates of the competition coefficient in individual studies

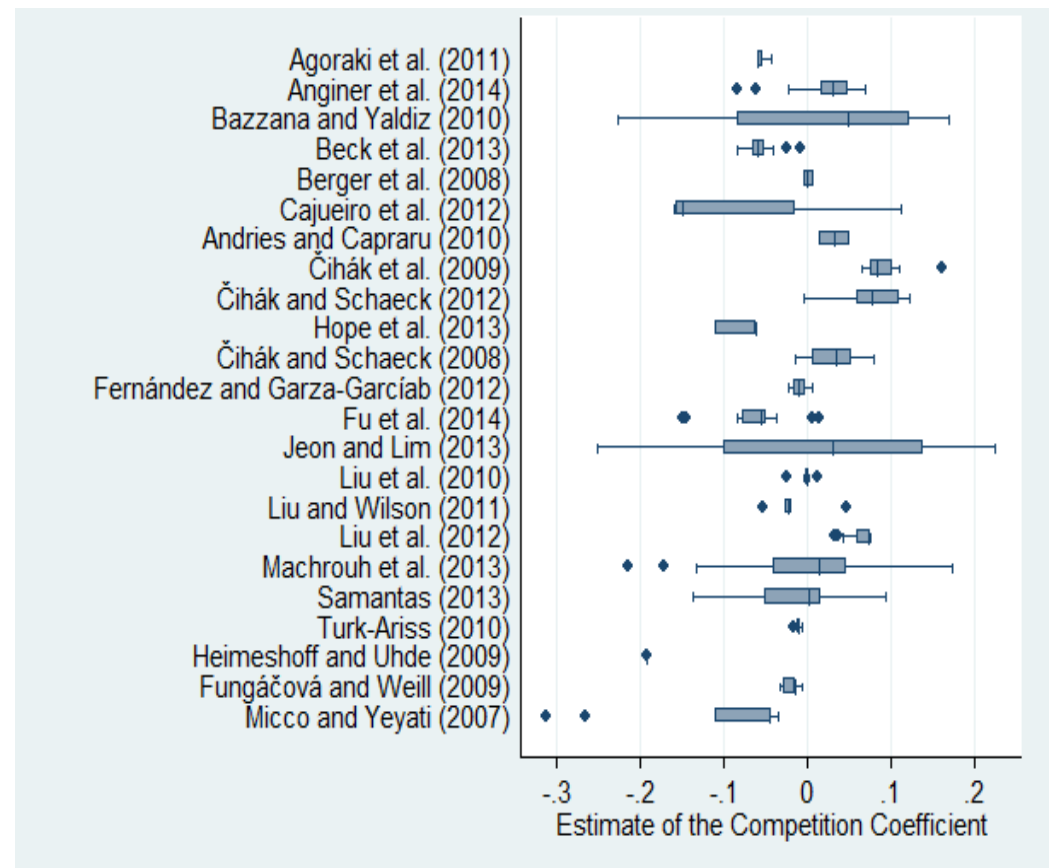

Notes: The figure shows a box plot of the PCCs of the competition coefficient estimates reported in individual studies when the concentrationstability estimates are omitted. Full references for the studies included in the meta-analysis are available in Appendix B.

Following the structure of the main analysis, Table 9 presents the simple means of the PCCs of the pure competition coefficient estimates for all countries as well as for developed and developing economies. The means of the estimates weighted by the inverse of the number of 
estimates reported per study are negative for all country groups, though they are again close to 0 and not significant at the 5\% level (and not economically significant according to the guidelines by Doucouliagos, 2011). The unweighted means are, on the other hand, positive, but also close to 0 and insignificant. Both the weighted and unweighted means appear to be slightly larger for developed countries, as was the case in the baseline analysis as well.

Table 9: Simple means of the PCCs of the pure competition coefficient estimates

\begin{tabular}{|c|c|c|c|c|c|c|c|}
\hline & \multicolumn{3}{|c|}{ Unweighted } & \multicolumn{3}{|c|}{ Weighted } & \multirow{2}{*}{$\begin{array}{l}\text { No. of } \\
\text { estimates }\end{array}$} \\
\hline & Mean & $95 \% \mathrm{Co}$ & Interval & Mean & $95 \% \mathrm{C}$ & Interval & \\
\hline All & 0.001 & -0.019 & 0.021 & -0.016 & -0.041 & 0.009 & 345 \\
\hline Developed & 0.011 & -0.009 & 0.030 & -0.008 & -0.049 & 0.033 & 109 \\
\hline and transition & 0.004 & -0.036 & 0.044 & -0.024 & -0.061 & 0.012 & 83 \\
\hline
\end{tabular}

Notes: The table presents the mean PCCs of the competition coefficient estimates (the PCCs of the $\beta$ estimates from equation (1)) over all countries and for selected country groups. The confidence intervals around the mean are constructed using standard errors clustered at the study level. In the right-hand part of the table the estimates are weighted by the inverse of the number of pure competition estimates reported per study.

Following the main analysis in Section 4, we test for the presence of publication bias in the literature. Figure 9 presents funnel plots for all the estimates and for the median estimates per study. It appears that the funnels are quite symmetrical and that positive and negative estimates, as well as significant and insignificant estimates, are reported in the literature. Overall, visual examination of the data does not point to strong publication bias.

Figure 9: Funnel plots do not suggest substantial publication bias

A: All estimates

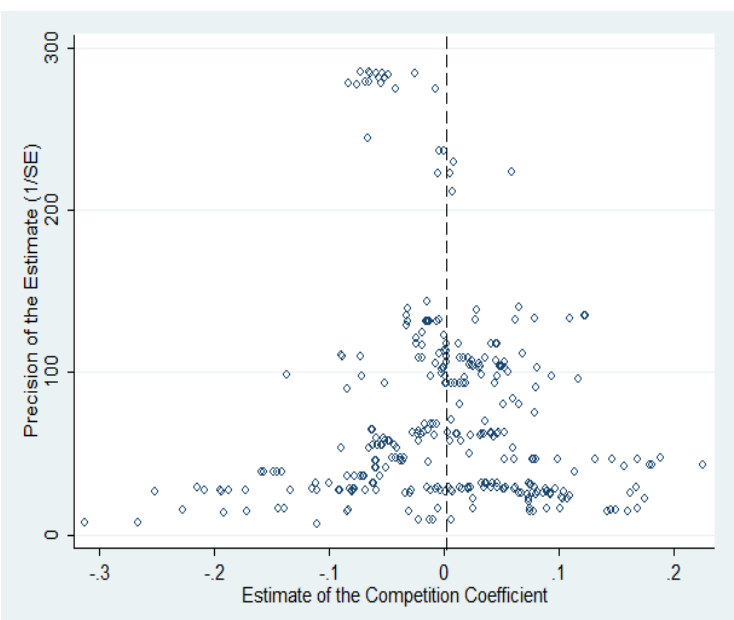

B: Median estimates per study

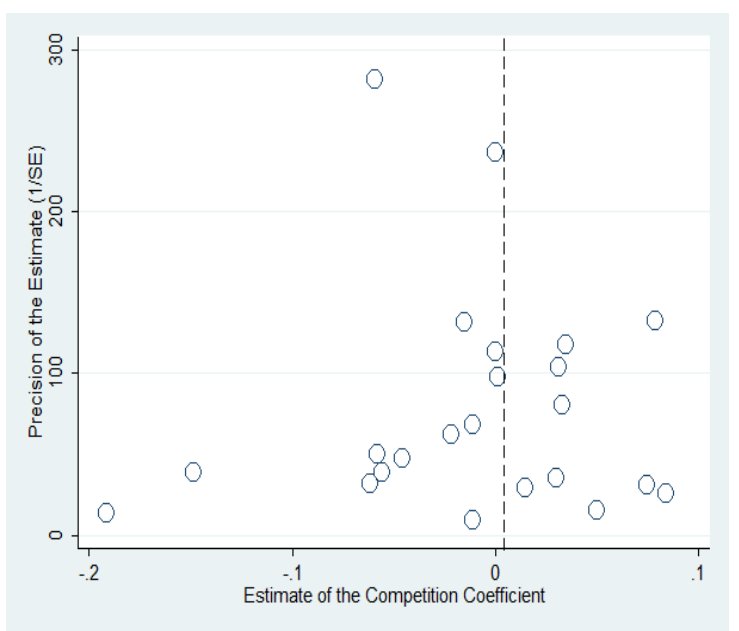

Notes: In the absence of publication bias the funnel should be symmetrical around the most precise PCC of the estimates of the competition coefficient (the PCCs of the $\beta$ estimates from equation (1)). The dashed vertical lines denote the mean of the PCCs of all the estimates in Figure $9 \mathrm{~A}$ and the mean of the median PCCs of the estimates reported in the studies in Figure 9B. 
Next, we turn to a more formal test for the presence of publication bias: the funnel asymmetry test. We follow the steps explained in detail in Section 4 and investigate if there is a correlation between the pure competition coefficient estimates (that is, after excluding the concentrationstability estimates) and their standard errors. Table 10 reports the results. The estimates obtained in all the regressions are very similar to those for the whole sample in Table 2. The estimates of the underlying effect beyond the bias are all significant at least at the $5 \%$ level, but again close to zero. According to Doucouliagos' (2011) guidelines, these estimates point to no interplay between competition and stability. In a similar vein, the new regressions yield comparable estimates of publication bias to those of the whole sample. In contrast to the main analysis, however, the magnitude of the publication bias for estimates reported in published studies does not appear to be higher than that for unpublished manuscripts. Moreover, the underlying effect beyond publication bias also does not seem to differ between published and unpublished studies.

Table 10: Funnel asymmetry tests suggest the presence of publication bias

\begin{tabular}{ccc|cc} 
Unweighted regressions & FE & FE_Published & Instr & Instr_Published \\
\hline SE (publication bias) & $-1.855^{* *}$ & $-1.881^{* *}$ & $-2.059^{* * *}$ & $-2.237^{* * *}$ \\
Constant (effect beyond bias) & $0.048^{* *}$ & $0.054^{* *}$ & $0.053^{* * *}$ & $0.064^{* * *}$ \\
No. of estimates & 345 & 272 & 345 & 272 \\
No. of studies & 23 & 17 & 23 & 17 \\
\hline Weighted regressions & \multicolumn{2}{c|}{ FE } & \multicolumn{2}{c}{ FE_Published } \\
\hline SE (publication bias) & $-1.683^{* * *}$ & \multicolumn{2}{c}{$-1.697^{* * *}$} \\
Constant (effect beyond bias) & $0.032^{* * *}$ & \multicolumn{2}{c}{$0.026^{* * *}$} \\
No. of estimates & 345 & 272 \\
No. of studies & \multicolumn{2}{c|}{23} & \multicolumn{2}{c}{17} \\
\hline
\end{tabular}

Notes: The table presents the results of equation (6). The standard errors of the regression parameters are clustered at the study level. Published = we only include published studies. Fixed Effects $=$ we use study dummies. Instrument $=$ we use the logarithm of the number of observations in equation (1) as an instrument for the standard error and employ study fixed effects. The regressions in the bottom half of the table are estimated by weighted least squares, where the inverse of the number of estimates reported per study is taken as the weight. ${ }^{* * *},{ }^{* *}$, and ${ }^{*}$ denote statistical significance at the $1 \%, 5 \%$, and $10 \%$ level.

Table 11 presents the results of the heteroskedasticity-corrected funnel asymmetry tests. By weighting the equations by precision, the estimation now places more weight on more precise pure competition coefficient estimates. In contrast to the main analysis in Table 3, the evidence for publication bias now appears to be widespread across different estimation techniques and specifications. The estimates of the magnitude of publication bias are also larger in absolute terms and statistically significant at least at the $10 \%$ level. In line with the main analysis, the estimates of the true effect are similar to those presented in the previous table, and are close to zero. According to the guidelines of Doucouliagos and Stanley (2013) for interpreting the funnel asymmetry test, our results point to substantial publication bias when we exclude all concentration-stability estimates. 
Table 11: Heteroskedasticity-corrected funnel asymmetry tests

\begin{tabular}{ccc|cc} 
Unweighted regressions & FE & FE_Published & Instr & Instr_Published \\
\hline 1/SE (effect beyond bias) & 0.024 & $0.064^{*}$ & $0.039^{* *}$ & $0.050^{* *}$ \\
Constant (publication bias) & $-2.210^{*}$ & $-4.651^{*}$ & $-3.285^{* *}$ & $-3.744^{* * *}$ \\
No. of estimates & 345 & 272 & 345 & 272 \\
No. of studies & 23 & 17 & 23 & 17 \\
\hline Weighted regressions & \multicolumn{2}{c|}{ FE } & \multicolumn{2}{c}{ FE_Published } \\
\hline 1/SE (effect beyond bias) & \multicolumn{2}{c|}{0.021} & $0.062^{* *}$ \\
Constant (publication bias) & $-2.207^{*}$ & $-5.369^{* *}$ \\
No. of estimates & 345 & 272 \\
No. of studies & 23 & 17 \\
\hline
\end{tabular}

Notes: The table presents the results of the regression specified in equation (7). The standard errors of the regression parameters are clustered at the study level. Published $=$ we only include published studies. Fixed Effects = we use study dummies. Instrument $=$ we use the logarithm of the number of observations in equation (1) as an instrument for the standard error and employ study fixed effects. The regressions in the bottom half of the table are estimated by weighted least squares, where the inverse of the number of estimates reported per study is taken as the weight. ${ }^{* * *},{ }^{* *}$, and ${ }^{*}$ denote statistical significance at the $1 \%, 5 \%$, and $10 \%$ level.

Finally, following the baseline analysis, we apply the "best-practice" estimation described at the end of Section 5 to the subsample containing only pure competition coefficient estimates. Due to insufficient convergence of the MCMC algorithm to the underlying analytical distribution in the BMA exercise for the reduced data set, a new set of variables influencing the pure competition coefficient cannot be determined. For this reason, we use the same definition of best practice and plug in the sample means and sample maxima for the same variables as discussed in Section 5, but using OLS estimates for the more homogeneous data set. The resulting coefficients are presented in Table 12. For both weighted and unweighted equations, the estimated competition coefficient for developed countries is again larger than that for developing and transition countries. Nevertheless, none of the estimates in Table 12 is significant at the $5 \%$ level. Overall, we conclude that, after collecting all estimates from the literature and applying various meta-analysis methods, there appears to be no apparent relationship between bank competition and financial stability.

Table 12: Best-practice estimates of the pure competition coefficient

\begin{tabular}{|c|c|c|c|c|c|c|c|c|}
\hline \multirow{2}{*}{ Best practice } & \multicolumn{4}{|c|}{ Weighted } & \multicolumn{4}{|c|}{ Unweighted } \\
\hline & Estimate & $95 \%$ & nf. Int. & Diff. & Estimate & $95 \% \mathrm{C}$ & ff. Int. & Diff. \\
\hline$\overline{\text { All }}$ & 0.014 & -0.046 & 0.075 & 0.030 & -0.033 & -0.067 & 0.001 & -0.034 \\
\hline Developed & 0.033 & -0.037 & 0.102 & 0.041 & 0.017 & -0.030 & 0.064 & 0.006 \\
\hline $\begin{array}{l}\text { Developing } \\
\text { and transition }\end{array}$ & 0.001 & -0.073 & 0.074 & 0.025 & 0.001 & -0.059 & 0.062 & -0.003 \\
\hline
\end{tabular}

Notes: The table presents estimates of the competition coefficient for selected country groups implied by the analysis of heterogeneity and our definition of best practice. We take the regression coefficients from the regression and construct fitted values of the competition coefficient conditional on control for publication characteristics and other aspects of methodology (see the main text for details). Diff. = the difference between these estimates and the means reported in Table 9. The confidence intervals are constructed using study-level clustered standard errors estimated by OLS. The right-hand part of the table presents results based on the robustness check using unweighted regressions (Table 8). 


\section{Concluding Remarks}

We conduct a meta-regression analysis of 598 estimates of the relationship between bank competition and financial stability reported in 31 studies. We complement the previous narrative reviews of the literature (Beck, 2008; Carletti and Hartmann, 2002) with a formal treatment of publication bias and heterogeneity in estimations of the competition-stability nexus. Our results suggest that the mean reported estimate of the relationship is close to zero, even after correcting for publication bias and potential misspecification problems. We find evidence for publication selection against positive results; that is, some authors of primary studies tend to discard estimates inconsistent with the competition-fragility hypothesis. To uncover the dependence of the reported estimates on the aspects of study design, we employ Bayesian model averaging, which helps us address model uncertainty.

Our results indicate that data characteristics matter for the reported coefficients corresponding to the competition-stability nexus. Researchers who use heterogeneous samples of countries (including both developed and developing economies) tend to obtain smaller estimates. The effect of competition on stability is larger in developed countries, but even there the positive effects do not seem to be strong. Next, accounting for potential nonlinearities in the effect of competition on stability is important and typically yields smaller estimates of the competitionstability nexus. We also find that, in general, researchers who have more data at their disposal tend to report smaller estimates.

Furthermore, we show that the definition of the proxy for financial stability is important for the results of primary studies. For example, if dummy variables (usually indicating financial crises) are used as a proxy for stability, the authors tend to report much larger estimates than when a continuous measure of financial stability is used. In a similar vein, the results of primary studies are systematically affected by the choice of the proxy for bank competition. Studies using the Hstatistic tend to report larger estimates of the competition-stability nexus, while studies that employ the Boone index usually show smaller estimates. Next, if the researchers ignore the endogeneity problem in regressing financial stability on bank competition, they tend to underestimate the effect.

We also find that controlling for supervisory and regulatory conditions in regressions usually decreases the reported estimates, which supports the notion that banking systems with more activity restrictions and greater barriers to entry are more likely to suffer from systemic financial distress (Beck et al., 2006 a,b). Finally, studies that receive more citations and are published in journals with a high impact factor tend to report larger estimates of the competition-stability nexus. In the last step of our analysis we construct a weighted average of all the estimates and give more weight to the ones whose authors avoid potential misspecifications (such as ignoring endogeneity) and that have better publication characteristics (for example, more citations). Because several potential misspecifications influence the results in opposite ways, the resulting estimate still points to a very weak or non-existent link between bank competition and financial stability. 
The principal limitation of meta-analysis is that it can only correct for problems in the literature that have already been addressed by some researchers. If, in contrast, all studies in the field share a common misspecification that causes a systematic bias, meta-analysis gives biased results as well. It is possible that the underlying effect of banking competition on financial stability is nonzero, but that the data and methods that are currently used in the literature do not allow researchers to identify such an effect. Nevertheless, we show that the bulk of the existing empirical literature provides little support for either the competition-fragility or competitionstability hypothesis.

\section{References}

Agoraki, M. K., Delis, M. D. \& Pasiouras, F., 2011. "Regulations, competition and bank risk-taking in transition countries.” Journal of Financial Stability 7(1): pp. 38-48.

Allen, F. \& Gale, D., 2000. "Comparing financial systems.” MIT Press, Cambridge, MA.

Allen, F. \& D. Gale, 2004. "Competition and financial stability." Journal of Money, Credit, and Banking 36: pp. 453-480.

Anginer, D., Demirguc-Kunt, A. \& Zhu, M., 2014. "How does competition affect bank systemic risk?" Journal of Financial Intermediation 23(1): pp. 1-26.

Ashenfelter, O., Harmon, C. \& Oosterbeek, H., 1999. "A review of estimates of the schooling/earnings relationship, with tests for publication bias.” Labour Economics 6(4): pp. 453-470.

Babecky, J. \& Havranek, T., 2014. "Structural reforms and growth in transition: A meta-analysis." Economics of Transition 22(1): pp. 13-42.

Barth, J. R., Caprio, Jr., G. \& Levine, R., 2004. "Bank supervision and regulation: What works best?" Journal of Financial Intermediation 13(2): pp. 205-248.

Bazzana, F. \& Yaldiz, E., 2010. "The effect of market power on bank risk taking in Turkey." Financial Theory and Practice 34(3): pp. 297-314.

Beck, T., 2008. "Bank competition and financial stability: Friends or foes?" Policy Research Working Paper Series 4656, The World Bank.

Beck, T., De Jonghe, O. \& Schepens, G., 2013. "Bank competition and stability: Cross-country heterogeneity." Journal of Financial Intermediation 22(2): pp. 218-244.

Beck, T., Demirguc-Kunt, A. \& Levine, R., 2006a. "Bank concentration, competition, and crises: First results.” Journal of Banking and Finance 30: pp. 1581-1603.

Beck, T., Demirguc-Kunt, A. \& Levine, R., 2006b. "Bank concentration and fragility: Impact and mechanics." In: Stulz, R. and M. Carey (eds), The Risks of Financial Institutions. National Bureau of Economic Research.

Berger, A. N., Klapper, L. \& Turk-Ariss, R., 2009. "Banking competition and financial stability.” Journal of Financial Services Research 35: pp. 99-118.

Bikker, J. A., 2004. "Competition and efficiency in a unified European banking market." Cheltenham, UK: Edward Elgar.

Boone, J., 2008. "A new way to measure competition.” Economic Journal 118: pp. 1245-1261.

Boot, A. \& Greenbaum, S., 1993. "Bank regulation, reputation and rents: Theory and policy implications." In: Mayer C. and X. Vives (eds), Capital Markets and Financial Intermediation, pp. 262-285. Cambridge: University Press.

Boot, A. W. A. \& Thakor, A. V., 1993. "Self-interested bank regulation." American Economic Review 83(2): pp. 206-212.

Boyd, J. \& De Nicolo, G., 2005. "The theory of bank risk-taking and competition revisited." Journal of Finance 60: pp. 1329-1342.

Boyd, J. H. \& Runkle, D. E., 1993. "Size and performance of banking firms: Testing the predictions of theory.” Journal of Monetary Economics 31(1): pp. 47-67. 
Boyd, J. H., De Nicolo, G. \& Jalal, A. M., 2006. "Bank risk-taking and competition revisited: New theory and new evidence.” IMF Working Paper No. 06/297.

Caminal, R. \& Matutes, C., 2002. "Market power and bank failures.” International Journal of Industrial Organisation 20: pp. 1341-1361.

Card, D. \& Krueger, A. B., 1995. "Time-series minimum wage studies: A meta-analysis." American Economic Review 85(2): pp. 238-243.

Carletti, E. \& Hartmann, P., 2002. "Competition and stability: What's special about banking?" Working Paper Series 0146, European Central Bank.

Chetty, R., Guren, A., Manoli, D. \& Weber, A., 2011. "Are micro and macro labour supply elasticities consistent? A review of evidence on the intensive and extensive margins.” American Economic Review 101(3): pp. 471-475.

Cipollini, A. \& Fiordelisi, F., 2009. "The impact of bank concentration on financial distress: The case of the European banking system.” Centro Studi di Banca e Finanza (CEFIN) (Center for Studies in Banking and Finance) 09021, Universita di Modena e Reggio Emilia, Facoltà di Economia "Marco Biagi".

Claessens, S. \& Laeven, L., 2004. "What drives bank competition? Some international evidence.” Journal of Money, Credit and Banking 36: pp. 563-83.

Cohen, J., 1988. Statistical Power Analysis in the Behavioral Sciences. 2nd ed. Hillsdale: Erlbaum.

De Nicolò, G. \& Loukoianova, E., 2007. "Bank ownership, market structure and risk." IMF Working Papers 07/215, International Monetary Fund.

DeLong, J. B. \& Lang, K., 1992. "Are all economic hypotheses false?" Journal of Political Economy 100(6): pp. 1257-1272.

Doucouliagos, H., 2011. "How large is large? Preliminary and relative guidelines for interpreting partial correlations in economics." Economics Series 2011/5, Deakin University, Faculty of Business and Law, School of Accounting, Economics and Finance.

Doucouliagos, H. \& Stanley, T. D., 2013. "Are all economic facts greatly exaggerated? Theory competition and selectivity.” Journal of Economic Surveys 27(2): pp. 316-339.

Doucouliagos, H. \& Stanley, T. D., 2009. "Publication selection bias in minimum wage research? A metaregression analysis.” British Journal of Industrial Relations 47(2): pp. 406-428.

Doucouliagos, H., Hama, J. \& Stanley, T. D., 2012. "Pay for performance and corporate governance reform.” Industrial Relations: A Journal of Economy and Society 51(3): pp. 670-703.

Egger, M., Smith, G. D., Scheider, M. \& Minder, C., 1997. "Bias in meta-analysis detected by a simple, graphical test.” British Medical Journal 316: pp. 629-634.

Eicher, T. S., Papageorgiou, C. \& Raftery, A. E., 2011. "Default priors and predictive performance in Bayesian model averaging, with application to growth determinants." Journal of Applied Econometrics 26(1): pp. 30-55.

Feldkircher, M. \& Zeugner, S., 2009. "Benchmark priors revisited: On adaptive shrinkage and the supermodel effect in Bayesian model averaging.” IMF Working Papers 09/202, International Monetary Fund.

Fernandez, C., Ley, E. \& Steel, M. F. J., 2001. “Benchmark priors for Bayesian model averaging.” Journal of Econometrics 100(2): pp. 381-427.

Fernandéz, R. O. \& Garza-García, J. G., 2012. "The relationship between bank competition and financial stability: A case study of the Mexican banking industry.” Centre for Global Finance Working Paper No. 03/12. University of the West of England.

Fungacova, Z. \& Weill, L., 2009. "How market power influences bank failures: Evidence from Russia." BOFIT Discussion Papers 12/2009, Bank of Finland, Institute for Economies in Transition.

Havranek, T. \& Kokes, O., 2014. "Income elasticity of gasoline demand: A meta-analysis." Energy Economics, forthcoming.

Hellman, T., Murdoch, K. \& Stiglitz, J. E., 2000. "Liberalization, moral hazard in banking and prudential regulation: Are capital requirements enough?” American Economic Review 90: pp. 147-165.

Keeley, M., 1990. "Deposit insurance, risk and market power in banking." American Economic Review 80: pp. 1183-2200.

Laeven, L. \& Levine, R., 2009. "Bank governance, regulation and risk taking.” Journal of Financial Economics 93: pp. 259-275.

Lepetit, L., Nys, E., Rous, P. \& Tarazi, A., 2008. "Bank income structure and risk: An empirical analysis of European banks.” Journal of Banking and Finance 32: pp. 1452-1467. 
Ley, E. \& Steel, M. F. J., 2009. "On the effect of prior assumptions in Bayesian model averaging with applications to growth regressions." Journal of Applied Econometrics 24(4): pp. 651-674.

Liu, H. \& Wilson, J. O. S., 2013. "Competition and risk in Japanese banking." European Journal of Finance 19(1): pp. 1-18.

Liu, H., Molyneux, P. \& Nguyen, L. H., 2012. "Competition and risk in South East Asian commercial banking." Applied Economics 44(28): pp. 3627-3644.

Marcus, A. J., 1984. "Deregulation and bank policy.” Journal of Banking and Finance 8: pp. 557-565.

Matutes, C. \& Vives, X., 2000. "Imperfect competition, risk taking and regulation in banking." European Economic Review 44: pp. 1-34.

Mishkin, F. S., 1999. "Financial consolidation: Dangers and opportunities." Journal of Banking and Finance 23: pp. 675-691.

Panzar, J. C. \& Rosse, J. N., 1987. "Testing for monopoly equilibrium.” Journal of Industrial Economics 35: pp. 443-456.

Pearson, K., 1904. "Report on certain enteric fever inoculation statistics." British Medical Journal 2(2288): pp. 1243-1246.

Raftery, A. E., Madigan, D. \& Hoeting, J. A., 1997. "Bayesian model averaging for linear regression models.” Journal of the American Statistical Association 92: pp. 179-191.

Rosenthal, R., 1979. "The 'file drawer problem' and tolerance for null results.” Psychological Bulletin 86: pp. 638-641.

Schaeck, K. \& Cihak, M., 2014. "Competition, efficiency, and stability in banking." Financial Management 43: pp. 215-241.

Schaeck, K. \& Cihak, M., 2012. "Banking competition and capital ratios." European Financial Management 18(5): pp. 836-866.

Schaeck, K., Cihak, M. \& Wolfe, S., 2009. “Are competitive banking systems more stable?” Journal of Money, Credit and Banking 41(4): pp. 711-734.

Stanley, T. D, 2001. "Wheat from chaff: Meta-analysis as quantitative literature review." Journal of Economic Perspectives 15(3): pp. 131-150.

Stanley, T. D., 2008. "Meta-regression methods for detecting and estimating empirical effects in the presence of publication selection." Oxford Bulletin of Economics and Statistics 70(1): pp. 103-127.

Stanley, T. D. \& Doucouliagos, H., 2012. "Meta-regression analysis in economics and business." Routledge Advances in Research Methods.

Stanley, T. D., Doucouliagos, H., Giles, M., Heckemeyer, J. H., Johnston, R. J., Laroche, P., Nelson, J. P., Paldam, M., Poot, J., Pugh, G., Rosenberger, R. S. \& Rost, K., 2013. "Meta-analysis of economics research reporting guidelines.” Journal of Economic Surveys 27(2): pp. 390-394.

Uhde, A. \& Heimeshoff, U., 2009. "Consolidation in banking and financial stability in Europe: Empirical evidence.” Journal of Banking and Finance 33: pp. 1299-1311.

Valickova, P., Havranek, T. \& Horvath, R., 2014. "Financial development and economic growth: A metaanalysis." Journal of Economic Surveys, forthcoming.

Yeyati, E. L. \& Micco, A., 2007. "Concentration and foreign penetration in Latin American banking sectors: Impact on competition and risk.” Journal of Banking and Finance 31: pp. 1633-1647. 


\section{Appendix A: BMA Diagnostics}

Table A1: Summary of BMA estimation, baseline estimation

\begin{tabular}{ccccc}
\hline Mean no. regressors & Draws & Burnins & Time & No. models visited \\
\hline 16.7873 & 2.00E+06 & 1.00E+06 & 8.946665 mins & 428100 \\
Modelspace $2 \wedge K$ & \% visited & \% Topmodels & Corr PMP & No. Obs. \\
\hline 3.4e+10 & 0.0012 & 85 & 0.9991 & 598 \\
Model Prior & & g-Prior & Shrinkage-Stats \\
\hline uniform / 17.5 & UIP & \multicolumn{2}{c}{ Av $=0.9983$} \\
\hline
\end{tabular}

Notes: In this specification we employ the priors suggested by Eicher et al. (2011) based on predictive performance: the uniform model prior (each model has the same prior probability) and the unit information prior (the prior provides the same amount of information as one observation of data).

Figure A1: Model size and convergence, baseline estimation
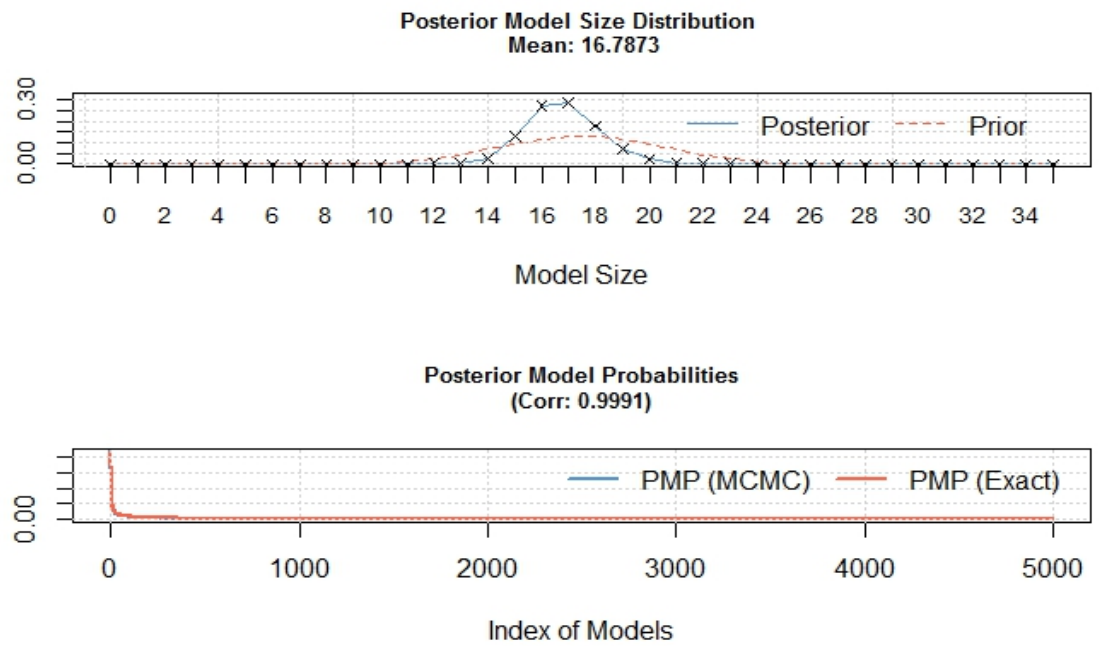

Table A2: Summary of BMA estimation, alternative priors

\begin{tabular}{ccccc}
\hline Mean no. regressors & Draws & Burnins & Time & No. models visited \\
\hline 15.9075 & $2.00 \mathrm{E}+06$ & $1.00 \mathrm{E}+06$ & 9.343995 mins & 340418 \\
Modelspace $2 \wedge \mathrm{K}$ & \% visited & \% Topmodels & Corr PMP & No. Obs. \\
\hline 3.4e+10 & 0.00099 & 92 & 0.9991 & 598 \\
Model Prior & & g-Prior & \multicolumn{2}{c}{ Shrinkage-Stats } \\
\hline random / 17.5 & BRIC & \multicolumn{2}{c}{ Av $=0.9992$} \\
\hline
\end{tabular}

Notes: The "random" model prior refers to the beta-binomial prior used by Ley \& Steel (2009): the prior model probabilities are the same for all possible model sizes. In this specification we set Zellner's $g$ prior in line with Fernandez et al. (2001). 
Figure A2: Model size and convergence, alternative priors
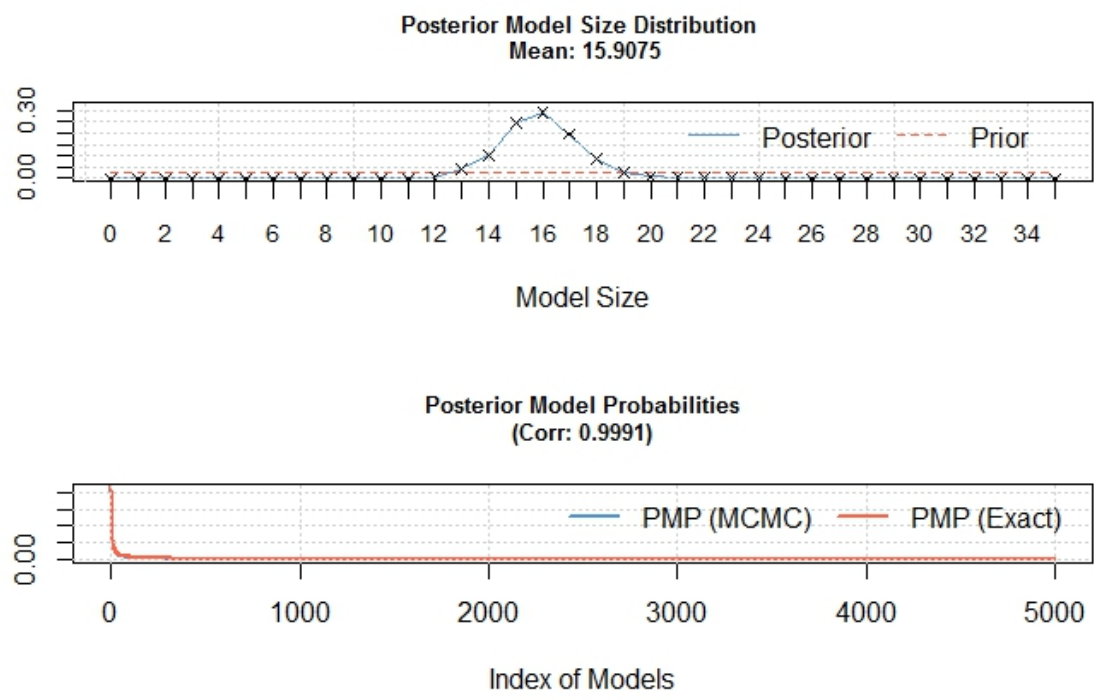

Table A3: Summary of BMA estimation, unweighted regressions

\begin{tabular}{|c|c|c|c|c|}
\hline Mean no. regressors & Draws & Burnins & Time & No. models visited \\
\hline 17.3680 & $2.00 \mathrm{E}+06$ & $1.00 \mathrm{E}+06$ & $9.077281 \mathrm{mins}$ & 543559 \\
\hline Modelspace $2 \wedge K$ & $\%$ visited & $\%$ Topmodels & Corr PMP & No. Obs. \\
\hline $3.4 \mathrm{e}+10$ & 0.0016 & 69 & 0.9961 & 598 \\
\hline Model I & & $g$-Prior & \multicolumn{2}{|c|}{ Shrinkage-Stats } \\
\hline uniform / & & UIP & \multicolumn{2}{|c|}{$\mathrm{Av}=0.9983$} \\
\hline
\end{tabular}

Notes: In this specification we employ the priors suggested by Eicher et al. (2011) based on predictive performance: the uniform model prior (each model has the same prior probability) and the unit information prior (the prior provides the same amount of information as one observation of data).

Figure A3: Model size and convergence, unweighted regressions
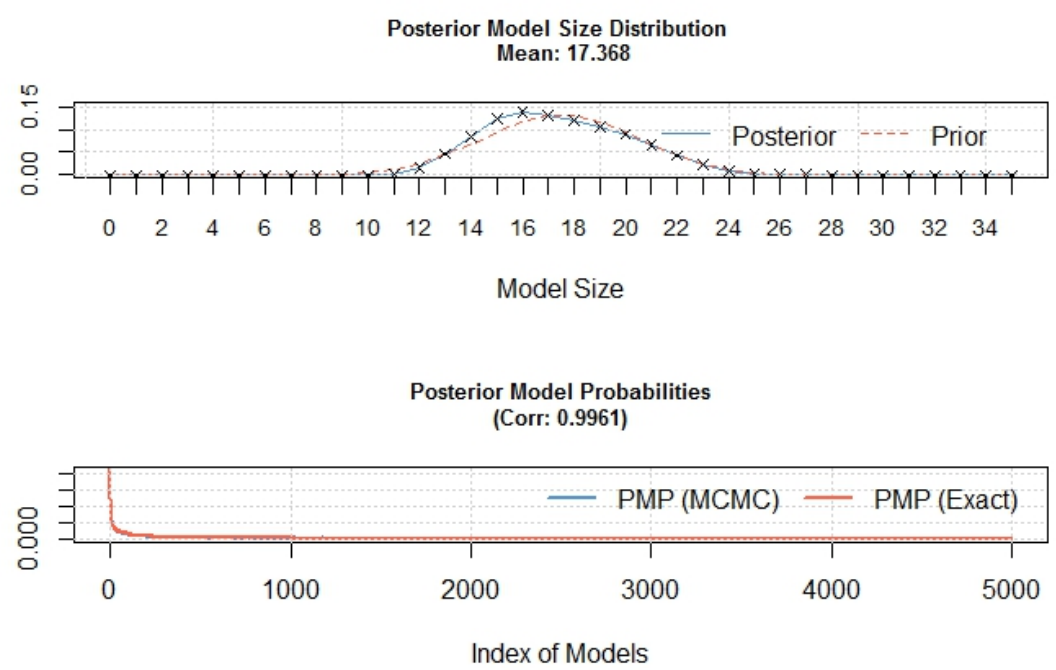


\section{Appendix B: Studies Included in the Meta-Analysis}

Agoraki, M.-E. K., Delis, M. D. \& Pasiouras, F., 2011. "Regulations, competition and bank risk-taking in transition countries.” Journal of Financial Stability 7(1): pp. 38-48.

Andries, M. A. \& Capraru, B., 2010. "How does EU banking competition impact financial stability?" Mimeo.

Anginer, D., Demirguc-Kunt, A. \& Zhu, M., 2014. "How does competition affect bank systemic risk?" Journal of Financial Intermediation 23(1): pp. 1-26.

Bazzana, F. \& Yaldiz, E., 2010. "The effect of market power on bank risk taking in Turkey." Financial Theory and Practice 34(3): pp. 297-314.

Beck, T., De Jonghe, O. \& Schepens, G., 2013. "Bank competition and stability: Cross-country heterogeneity." Journal of Financial Intermediation 22(2): pp. 218-244.

Beck, T., Demirguc-Kunt, A. \& Levine, R., 2006a. "Bank concentration, competition, and crises: First results.” Journal of Banking and Finance 30: pp. 1581-1603.

Beck, T., Demirguc-Kunt, A. \& Levine, R., 2006b. "Bank concentration and fragility: Impact and mechanics." In: Stulz, R. and M. Carey (eds), The Risks of Financial Institutions. National Bureau of Economic Research.

Berger, A. N., Klapper, L. \& Turk-Ariss, R., 2009. "Banking competition and financial stability.” Journal of Financial Services Research 35: pp. 99-118.

Boyd, J. H., De Nicolo, G. \& Jalal, A. M., 2006. "Bank risk-taking and competition revisited: New theory and new evidence." IMF Working Paper No. 06/297.

Cihak, M. \& Hesse, H., 2010. "Islamic banks and financial stability: An empirical analysis." Journal of Financial Services Research 38: pp. 95-113.

Cipollini, A. \& Fiordelisi, F., 2009. "The impact of bank concentration on financial distress: The case of the European banking system.” Centro Studi di Banca e Finanza (CEFIN) (Center for Studies in Banking and Finance) 09021, Universita di Modena e Reggio Emilia, Facoltà di Economia "Marco Biagi".

De Nicolò, G. \& Loukoianova, E., 2007. "Bank ownership, market structure and risk.” IMF Working Papers 07/215, International Monetary Fund.

Deltuvaite, V., 2012. "The concentration-stability relationship in the banking system: An empirical research.” Economics and Management 17(3): pp. 869-878.

Fernandez, R. O. \& Garza-Garciab, J. G., 2012. "The relationship between bank competition and financial stability: A case study of the Mexican banking industry." Centre for Global Finance Working Paper No. 03/12. University of the West of England.

Fu, X., Lin, Y. \& Molyneux, P., 2014. "Bank competition and financial stability in Asia Pacific." Journal of Banking and Finance 38(C): pp. 64-77.

Fungacova, Z. \& Weill, L., 2009. "How market power influences bank failures: Evidence from Russia." BOFIT Discussion Papers 12/2009, Bank of Finland, Institute for Economies in Transition.

Hope, J. C., Gwatidzo, T. \& Ntuli, M., 2013. "Investigating the effect of bank competition on financial stability in 10 African countries." International Business \& Economics Research Journal 12(7): pp. 755768.

Iskenderoglu, O. \& Tomak, S., 2013. "Competition and stability: An analysis of the Turkish banking system.” International Journal of Economics and Financial Issues 3(3): pp. 752-762.

Jeon, J. Q. \& Lim, K. K., 2013. Bank competition and financial stability: A comparison of commercial banks and mutual savings banks in Korea. Pacific-Basin Finance Journal, Elsevier, vol. 25(C), pp. 253-272.

Levy Yeyati, E. \& Micco, A., 2007. "Concentration and foreign penetration in Latin American banking sectors: Impact on competition and risk.” Journal of Banking and Finance 31: pp. 1633-1647.

Liu, H. \& Wilson, J. O. S., 2013. "Competition and risk in Japanese banking." European Journal of Finance 19(1): pp. 1-18.

Liu, H., Molyneux, P. \& Nguyen, L. H., 2012. "Competition and risk in South East Asian commercial banking." Applied Economics 44(28): pp. 3627-3644.

Molyneux, P., Liu, H. \& Wilson, J. O. S., 2010. "Competition and stability in European banking: A regional analysis." Working Papers 10019, Bangor Business School, Prifysgol Bangor University (Cymru/Wales).

Samantas, I., 2013. "Bank competition and financial (in)stability in Europe: A sensitivity analysis." MPRA 
Paper 51621, University Library of Munich, Germany.

Schaeck, K. \& Cihak, M., 2008. "How does competition affect efficiency and soundness in banking? New empirical evidence.” Working Paper No. 932, European Central Bank.

Schaeck, K. \& Cihak, M., 2014. "Competition, efficiency, and stability in banking." Financial Management 43: pp. 215-241.

Schaeck, K., Cihak, M. \& Wolfe, S., 2009. "Are competitive banking systems more stable?” Journal of Money, Credit and Banking 41(4): pp. 711-734.

Soedarmono, W., Machrouh, F. \& Tarazi, A., 2013. "Bank competition, crisis and risk taking: Evidence from emerging markets in Asia.” Journal of International Financial Markets, Institutions and Money 23(C): pp. 196-221.

Tabak, B. M., Fazio, D. M. \& Cajueiro, D. O., 2012. "The relationship between banking market competition and risk-taking: Do size and capitalization matter?" Journal of Banking and Finance 36(12): pp. 3366-3381.

Turk Ariss, R., 2010. "On the implications of market power in banking: Evidence from developing countries.” Journal of Banking and Finance 34(4): pp. 765-775.

Uhde, A. \& Heimeshoff, U., 2009. "Consolidation in banking and financial stability in Europe: Empirical evidence.” Journal of Banking and Finance 33(7): pp. 1299-1311. 


\section{DAVIDSON INSTITUTE WORKING PAPER SERIES - Most Recent Papers}

The entire Working Paper Series may be downloaded free of charge at: www.wdi.umich.edu

CURRENT AS OF 1/27/15

\begin{tabular}{|c|c|c|}
\hline Publication & Authors & Date \\
\hline $\begin{array}{l}\text { No. 1087: Bank Competition and Financial Stability: Much Ado About } \\
\text { Nothing? }\end{array}$ & $\begin{array}{l}\text { Diana Zigraiova and } \\
\text { Tomas Havranek }\end{array}$ & Jan 2015 \\
\hline $\begin{array}{l}\text { No. 1086: What incentives are being used by International Business } \\
\text { Researchers in Their Surveys? A Review. }\end{array}$ & $\begin{array}{l}\text { Agnieszka Chidlow and } \\
\text { Pervez N. Ghauri }\end{array}$ & Dec 2014 \\
\hline $\begin{array}{l}\text { No. 1085: Capital Account Policies, IMF Programs and Growth in } \\
\text { Developing Regions }\end{array}$ & $\begin{array}{l}\text { Zorobabel Bicaba, Zuzana } \\
\text { Brixiová and Mthuli Ncube }\end{array}$ & Nov 2014 \\
\hline $\begin{array}{l}\text { No. 1084: Testing the causality between electricity consumption, energy } \\
\text { use and education in Africa }\end{array}$ & $\begin{array}{c}\text { Oussama BEN ABDELKARIM, } \\
\text { Adel BEN YOUSSEF, } \\
\text { Hatem M'HENNI and } \\
\text { Christophe RAULT }\end{array}$ & Sept 2014 \\
\hline $\begin{array}{l}\text { No. 1083: Measuring and analyzing the non-monetary approach of } \\
\text { multidimensional poverty by the basic needs in Togo }\end{array}$ & Yawo Agbényégan NOGLO & Aug 2014 \\
\hline $\begin{array}{l}\text { No. 1082: Liquidity Constraints, Loss Aversion, and Myopia: Evidence } \\
\text { from Central and Eastern European Countries }\end{array}$ & Ramiz Rahmanov & Aug 2014 \\
\hline $\begin{array}{l}\text { No. 1081: The Real Exchange Rate and Growth in Zimbabwe: Does the } \\
\text { Currency Regime Matter? }\end{array}$ & $\begin{array}{l}\text { Zuzana Brixiová and Mthuli } \\
\text { Ncube }\end{array}$ & Aug 2014 \\
\hline $\begin{array}{l}\text { No. 1080: Recent Estimates of Exchange Rate Pass-Through to } \\
\text { Import Prices in the Euro Area }\end{array}$ & $\begin{array}{l}\text { Nidhaleddine Ben Cheikh and } \\
\text { Christophe Rault }\end{array}$ & Aug 2014 \\
\hline No. 1079: How smooth is the stock market integration of CEE-3? & $\begin{array}{l}\text { Eduard Baumöhl and } \\
\text { Štefan Lyócsa }\end{array}$ & June 2014 \\
\hline $\begin{array}{l}\text { No. 1078: The Role of the Business Cycle in Exchange } \\
\text { Rate Pass-Through: The Case of Finland }\end{array}$ & $\begin{array}{l}\text { Nidhaleddine Ben Cheikh and } \\
\text { Christophe Rault }\end{array}$ & June 2014 \\
\hline $\begin{array}{l}\text { No. 1077: Skills and youth entrepreneurship in Africa: Analysis with } \\
\text { evidence from Swaziland }\end{array}$ & $\begin{array}{l}\text { Zuzana Brixiova, Mthuli Ncube \& } \\
\text { Zorobabel Bicaba }\end{array}$ & May 2014 \\
\hline $\begin{array}{l}\text { No. 1076: Can Dreams Come True? Eliminating Extreme Poverty In } \\
\text { Africa By } 2030\end{array}$ & $\begin{array}{l}\text { Mthuli Ncube, Zuzana Brixiova } \\
\text { \& Zorobabel Bicaba }\end{array}$ & April 2014 \\
\hline $\begin{array}{l}\text { No. 1074: Bridging the Gender Gap in Entrepreneurship: Evidence from } \\
\text { Europe }\end{array}$ & Elvin Afandi \& Majid Kermani & Feb 2014 \\
\hline $\begin{array}{l}\text { No. 1073: Can Intra-Regional Trade Act as a Global Shock Absorber } \\
\text { in Africa? }\end{array}$ & $\begin{array}{l}\text { Mthuli Ncube, Zuzana Brixiova } \\
\text { \& Qingwei Meng }\end{array}$ & Feb 2014 \\
\hline No. 1072: The Dynamics of Firm Lobbying & $\begin{array}{l}\text { William R. Kerr, William F. } \\
\text { Lincoln and Prachi Mishra }\end{array}$ & Jan 2014 \\
\hline $\begin{array}{l}\text { No. 1071: Skilled Immigration and the Employment Structures of U.S. } \\
\text { Firms }\end{array}$ & $\begin{array}{l}\text { Sari Pekkala Kerr, William R. } \\
\text { Kerr and William F. Lincoln }\end{array}$ & Jan 2014 \\
\hline $\begin{array}{l}\text { No. 1070: Exchange Rate Pass-Through to Domestic Prices } \\
\text { under Different Exchange Rate Regimes }\end{array}$ & Rajmund Mirdala & Jan 2014 \\
\hline $\begin{array}{l}\text { No. 1069: Ailing Mothers, Healthy Daughters? Contagion } \\
\text { in the Central European Banking Sector }\end{array}$ & Tomas Fiala \& Tomas Havranek & Jan 2014 \\
\hline
\end{tabular}

